Article

\title{
Experimental Evaluation of Radiant Heating Ceiling Systems Based on Thermal Comfort Criteria
}

\author{
M. Reza Safizadeh *(1), Marcel Schweiker and Andreas Wagner(D) \\ Building Science Group (fbta), Institute for Building Design and Technology, Karlsruhe Institute of Technology (KIT), \\ 76131 Karlsruhe, Germany; marcel.schweiker@kit.edu (M.S.); wagner@kit.edu (A.W.) \\ * Correspondence: reza.safi@kit.edu; Tel.: +49-721-608-46983
}

Received: 14 September 2018; Accepted: 23 October 2018; Published: 26 October 2018

\begin{abstract}
Low-temperature radiant heating systems can be considered as suitable candidates for the refurbishment of old heating systems. These systems are proven to save energy, however, their drawback is their impact on the creation of radiant temperature asymmetry and local thermal discomfort, especially in old buildings where the temperatures of surfaces (for example external walls with a low level of insulation and large windows) are low. This study aims to evaluate the potential application of low-temperature radiant ceiling heating systems $\left(28-38{ }^{\circ} \mathrm{C}\right)$ in old and energy-renovated buildings, based on subjective experiments and thermal comfort criteria such as thermal sensation, comfort, satisfaction, and sensation asymmetry votes. Later, in the Discussion section, the guideline for the radiant temperature asymmetry for the warm ceiling presented in ASHRAE Standard-55 is corrected for relatively low air temperatures and different surface temperatures corresponding to "about neutral" conditions for winter clothing. Findings of this research show that the radiant ceiling heating system operating at low temperatures $\left(33-38^{\circ} \mathrm{C}\right)$ can provide fairly neutral thermal sensation and satisfactory comfort at the majority of body-parts, if the building envelope satisfies advanced building energy-efficiency regulations. Additionally, the experimental analyses imply that limitation of $5 \%$ suggested by ASHRAE- 55 for the percentage of dissatisfied occupants feeling uncomfortable due to overhead radiation can be elevated to $10 \%$.
\end{abstract}

Keywords: radiant heating ceiling; radiant temperature asymmetry; thermal dissatisfaction; thermal comfort; subjective experiments

\section{Introduction}

Heating ceiling systems as a type of radiant heating systems are criticized for causing asymmetric thermal conditions and local discomfort [1,2]. This issue has been addressed by a few systematic studies [3-6]; however, a globally accepted criterion for radiant asymmetry with minimum dissatisfaction has not been defined. ASHRAE Standard-55, 2017 [7] only published a guidance, based on the studies done by Fanger and his team [5,8], to determine the maximum allowable radiant temperature asymmetry based on the percentage of dissatisfied people. In these studies, the influence of radiant heating ceiling system and the asymmetry on the thermal discomfort was tested in neutral conditions when sixteen participants were wearing summer clothing. The minimum (about zero) asymmetry temperature was obtained for the ceiling surface temperature of about $24{ }^{\circ} \mathrm{C}$ that was about the room air and other surfaces' temperatures. The increased ceiling surface temperature was balanced by a decrement of air and wall temperatures in a way that the operative temperature at the height of $60 \mathrm{~cm}$ was kept constant at about $24{ }^{\circ} \mathrm{C}$. At this neutral operative temperature, the ceiling surface temperature was increased from $24{ }^{\circ} \mathrm{C}$ to $65^{\circ} \mathrm{C}$ in five steps, which adversely affected thermal satisfaction. They suggested that the $5 \%$ of dissatisfaction is a limit for allowable radiant temperature asymmetry. This limit $(5 \%)$ was inspired by the predefined 
dissatisfaction limit in a uniform condition. In another study, Chrenko suggested $20 \%$ as the limit for satisfaction [3]. Zhang et al. [9] used an advanced comfort model to simulate radiant ceiling heating and cooling systems, and they concluded that the current limits specified in ASHRAE Standard-55 are too restrictive.

McNall and Biddison studied the influence of radiant temperature asymmetry created by different wall and ceiling surface temperatures on thermal sensation and comfort criteria [10]. In their analyses, they eliminated the effect of local discomfort on the global discomfort by considering the comfort responses accompanied by the overall thermal sensation response of "neutral". In their study, $21 \%$ of the 16 participants felt uncomfortable with the room air temperature of $26{ }^{\circ} \mathrm{C}$ and the radiant temperature asymmetry of $4 \mathrm{~K}$ corresponding to the ceiling surface temperature of $54.4{ }^{\circ} \mathrm{C}$ and other surface temperatures of $16^{\circ} \mathrm{C}$. Griffiths and McIntyre tested the impact of a radiant heating ceiling system on the thermal comfort of a group of 24 participants [4]. The ceiling was set at 26.5, 30,38 and $45{ }^{\circ} \mathrm{C}$, the air temperature was kept constant at $21^{\circ} \mathrm{C}$, the operative temperature was between 21 and $22.9^{\circ} \mathrm{C}$ and the wall temperature was reduced as the ceiling surface temperature increased. At the highest radiant temperature asymmetry $\left(7.3^{\circ} \mathrm{C}\right)$, corresponding to the ceiling surface temperature of $45^{\circ} \mathrm{C}$ and the wall temperatures of $15^{\circ} \mathrm{C}$, all the participants were satisfied.

Moreover, concerning radiant temperature asymmetry, ASHRAE Standard-55 [7] and the study by Fanger [8] stated that in general people are more sensitive to asymmetric radiation caused by a radiant heating ceiling than that caused by a cold vertical surface such as a cold window. Some studies have suggested that occupants in the vicinity of cold windows with low thermal performance can suffer from the cold draft or radiant temperature asymmetry. For example, Underwood and Parsons [11] studied the effect of radiant temperature asymmetry created by a cold vertical surface (an artificial window) on the discomfort conditions of eight participants seated "side on" to the window. They proved that the cold window with the surface temperature of $5^{\circ} \mathrm{C}$ (clo: 0.7 ) could reduce the overall thermal sensation by 1 unit (7-point ASHRAE scale) from "neutral" to "slightly cool. A simulation study by Gan [12] suggested that while the single-glazed window creates the radiant asymmetry about $16 \mathrm{~K}$ in the vicinity of the cold window, the radiant asymmetry for a double glaze is less than $10 \mathrm{~K}$. They also suggested that thermal discomfort was less for a tall and narrow window compared to that for a square window. Larsson and Moshfegh experimentally proved that risk of draft can be reduced if a window with high thermal performance is applied [13]. A high-performance window has relatively high surface temperature due to minimum heat loss to the cold ambient air resulting in the relatively low risk of the draft and radiant temperature asymmetry.

The main challenge in the evaluation of radiant heating ceiling systems is the analysis of the thermal comfort criteria such as overall/local thermal sensation and comfort, and thermal satisfaction in asymmetric thermal environments created by the warm ceiling. In asymmetrical environments, thermal sensation and thermal comfort can be estimated mainly by the local skin temperatures and core temperatures [14]. Sakoi et al. [15] investigated local thermal comfort, skin temperatures and sensible heat losses at limited body-parts such as head and foot in anterior-posterior, right-left, and up-down asymmetric thermal environments created by radiation panels. They performed 35 experiments with 12 participants at different environmental conditions for the range of air temperatures between 25.5 and $30.5^{\circ} \mathrm{C}$, and surface temperatures between 11.5 to $44.5^{\circ} \mathrm{C}$. The study showed the complexity of the relation between local thermal discomfort and local skin temperatures and heat losses, and this relation depended on non-uniform conditions. For example, they indicated that the local heat discomfort at the head was in proportion to the local skin temperature, but in reverse proportion to the local sensible heat loss. However, the local cold discomfort in the foot area increased in reverse proportion to the local skin temperature. Wyon et al. [16] and Nilsson et al. [17] presented the concept of "Piste" for asymmetric conditions that relates the local thermal comfort status at 16 body parts to the equivalent homogeneous temperature (EHT). However, these models are limited to specific experimental conditions tested and EHT ranges are not related to the human physiological parameters such as local skin and core temperatures [18,19]. The advanced models such as dynamic thermal sensation (DTS) by Fiala [20] and 
thermal sensation (TS) by Zhang [14] have shown promising results, yet, for dominant convection heat process. However, they should be used with some consideration and validation for dominant radiant heat process. Concerning limitations on the use of existing thermal comfort models to describe the comfort criteria in the asymmetric thermal environment, a subjective experimental study is considered to evaluate ceiling heating systems based on subjective votes.

The review of the aforementioned studies and other review reports $[6,18]$ with regards to the performance of a warm radiant ceiling and a cold window does not answer the following practical questions:

1. Does the low-temperature radiant heating systems have the potential to be applied in a building with a window/façade that has poor or high thermal performance? In another word, to what extent can the application of the low-temperature radiant heating ceiling system and the cool/warm window provide thermal comfort for the occupants?

2. How does a type of glazing can influence the local thermal comfort criteria?

3. To what extent can the ceiling surface temperature of a heating system be reduced to diminish the radiant temperature asymmetry?

4. Finally, is the guidance for warm ceiling and cold vertical surface presented in ASHRAE-55 generalized for another room boundary and air conditions as well as different clothing insulation?

The goal of this study is addressing the aforementioned questions by means of subjective experiments. The next section of this paper is allocated to describe the methods. The Results section of this paper reports the analysis of experimentally obtained local thermal sensation and comfort votes, analyses for the discomfort limits based on the radiant temperature asymmetry, and the thermal sensation asymmetry in connection to the twelve scenarios; and Section 4 summarizes the results of this work and draws conclusions.

\section{Methods}

A set of subjective experiments in a controlled condition was designed in order to evaluate the influence of low-temperature radiant heating ceiling systems on the thermal comfort criteria in response to the quality of facade. The following sections describe the indoor climate test-facility, the experimental design, and the measurements.

\subsection{Experimental Facilities}

The experiments were performed in an indoor climate test facility (called LOBSTER) located at the Karlsruhe Institute of Technology (KIT) (Figure 1). A detailed description of the test facility was reported by Wagner et al. [21]. The acronym LOBSTER stands for the Laboratory for Occupant Behavior, Satisfaction, Thermal comfort, and Environmental Research. The LOBSTER is a rotatable structure consisting of two test-rooms $\left(4 \times 6 \times 3 \mathrm{~m}^{3}\right)$ that are connected to the outdoor environment via windows (total area $=12.6 \mathrm{~m}^{2}, \mathrm{U}$-value $=0.7 \mathrm{~W} / \mathrm{m}^{2} \cdot \mathrm{K}$ ) and a small preparation room for acclimation. The rooms surfaces are cooled or warmed by hydronic capillary tubes. Using this combination, the room surfaces can operate at different temperatures acting as heat sinks and heat sources. In order to minimize the effect of solar radiation on the window temperature and participants, the façade was rotated to the north. 


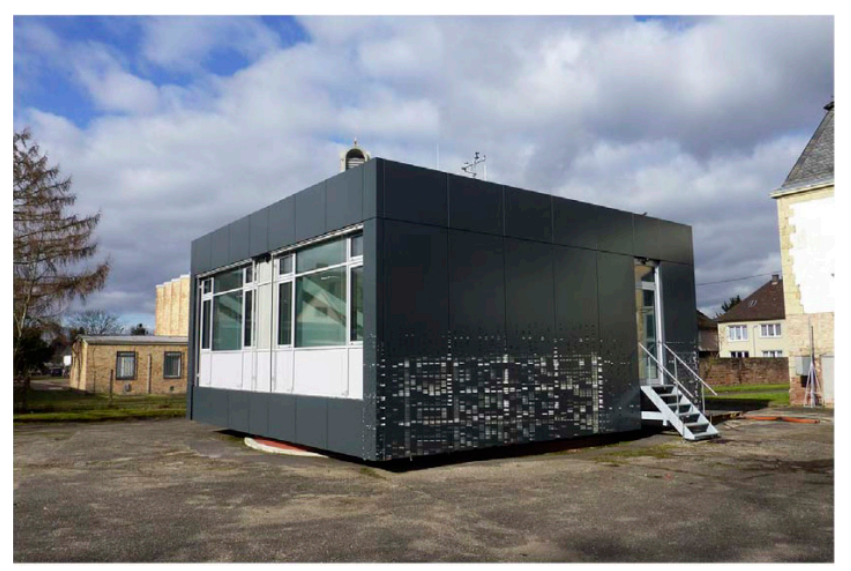

Figure 1. The 'LOBSTER' test facility: view from outside (a selected image).

\subsection{Experimental Procedures}

\subsubsection{Setting the Room Surface Temperatures}

We have learned from the pilot experiments conducted during the winter of 2016 [22] that the internal surface temperatures of the window and the exterior wall were highly dependent on the indoor air and the room surface temperatures, and their temperatures could not be less than $17.5^{\circ} \mathrm{C}$. This was because of the following facts:

(i) the U-value of the window and the façade below the window were relatively low (with the U-values of 0.7 and $0.2 \mathrm{~W} / \mathrm{m}^{2} \cdot \mathrm{K}$, respectively),

(ii) The internal surface of the window and façade absorbed radiation from the room surfaces, particularly from the warm radiant ceiling, and

(iii) The outside air temperature was between $-2{ }^{\circ} \mathrm{C}$ and $11^{\circ} \mathrm{C}$, which was relatively high for this period of winter.

Therefore, in order to imitate a poorly insulated façade with relatively cold temperatures and a high-performance façade with relatively warm temperatures, the interior south wall in the two rooms was selected to act as an artificial window and external façade. In this set of experiments, the south/front wall in room-A was cooled to $15.5^{\circ} \mathrm{C}$ in order to simulate the poor performance window and the south/front wall in another room (room-B) was set to $19{ }^{\circ} \mathrm{C}$ for imitating a window with high thermal performance. The lower part of the south wall was insulated for imitation of a façade having a higher temperature.

The rooms' internal surfaces including the floor and walls were set to $20^{\circ} \mathrm{C}$ in order to simulate the surface temperatures of a living room in a building with standard building envelope elements, an intermittent heating system, and the controlled room air temperature between 19 and $21^{\circ} \mathrm{C}$. The surface temperatures kept constant for the three predefined ceiling temperatures $\left(28,33\right.$ and $\left.38^{\circ} \mathrm{C}\right)$ for consistency in analyses of subjective votes and validation of future CFD models (see Table 1).

Table 1. Boundary conditions: set temperatures at inner surfaces.

\begin{tabular}{cccccc}
\hline $\begin{array}{c}\text { Ceiling } \\
\text { Temperatures } \\
\left({ }^{\circ} \mathrm{C}\right)\end{array}$ & $\begin{array}{c}\text { Artificial Window } \\
\text { Temperatures } \\
\left({ }^{\circ} \mathrm{C}\right)\end{array}$ & $\begin{array}{c}\text { Walls' } \\
\text { Temperatures } \\
\left({ }^{\circ} \mathbf{C}\right)\end{array}$ & $\begin{array}{c}\text { Floor } \\
\text { Temperature } \\
\left({ }^{\circ} \mathbf{C}\right)\end{array}$ & $\begin{array}{c}\text { Window } \\
\text { Temperature } \\
\left({ }^{\circ} \mathrm{C}\right)\end{array}$ & $\begin{array}{c}\text { Exterior Wall } \\
\text { under Window } \\
\left({ }^{\circ} \mathbf{C}\right)\end{array}$ \\
\hline $28,33,38$ & $15.5,19$ & 20 & 20 & $\mathrm{~T}^{*}$ & $\mathrm{~T}^{*}$ \\
\hline
\end{tabular}

$\mathrm{T} *$ is the temperature of the surface behind participants. It depends on outdoor and indoor conditions. 


\subsubsection{Experimental Design}

The experiments were performed with 30 young subjects (19-30 years old) including 14 females and 16 males. The experiments took place in three subsequent weeks from 4-22 December 2017. Figure 2 presents 12 scenarios which were designed based on three main factors including the ceiling surface temperature, the artificial window temperature and the distance to the window. The radiant ceiling was set to three values of 28,33 and $38^{\circ} \mathrm{C}$, two temperatures of 15.5 and $19^{\circ} \mathrm{C}$ were assigned to the artificial window (front wall) and the distances to the artificial window are $1 \mathrm{~m}$ and $3 \mathrm{~m}$. Figure 3 shows the schematic of two test-rooms including the set boundary conditions (given in Table 1) and the positions of the participants in respect to the relatively cool and warm front walls (artificial windows). The participants were positioned in a symmetric position with respect to the two sidewalls with the temperatures of $20^{\circ} \mathrm{C}$. The positions of the participants in the two rooms are switched according to the timeline shown in Figure 4. It is worth noting that that the height of the room is $3 \mathrm{~m}$ which is not representative for apartments in Germany built after 1945; however, Griffiths and McIntyre [4] mentioned that changing the height of the warm ceiling in the order of $0.5 \mathrm{~m}$ does not influence the perceived thermal comfort when the ceiling surface temperature is below $38^{\circ} \mathrm{C}$.

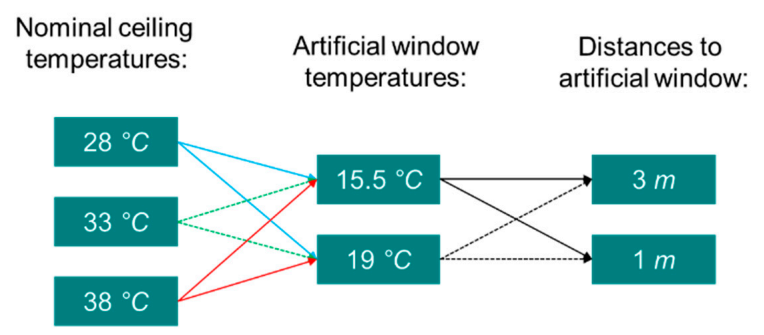

Figure 2. Experimental scenarios: a combination of three ceiling temperatures, two artificial window temperatures, and two distances to the artificial window. The scenarios are discussed in Section 2.3.

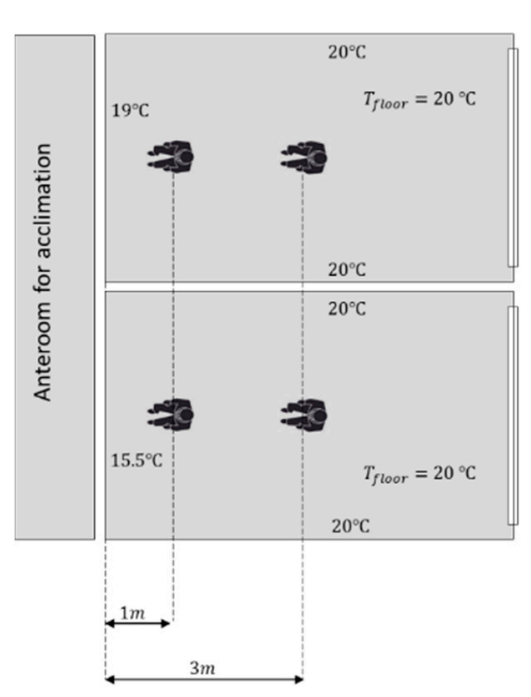

(a)

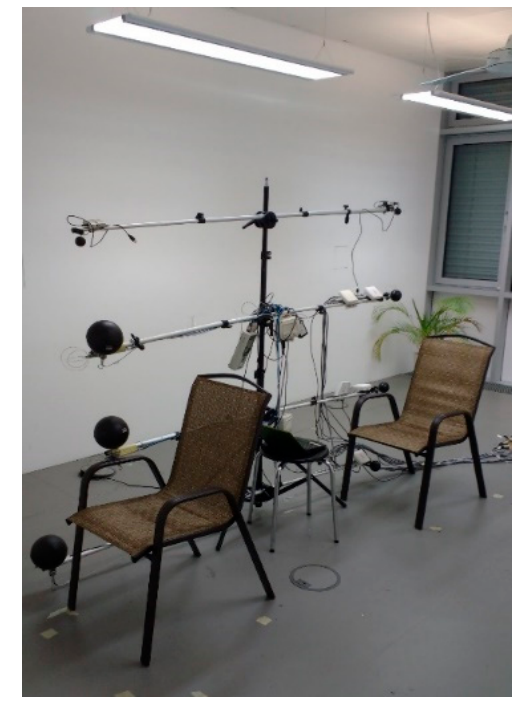

(b)

Figure 3. (a) Schematic of the LOBSTER (the two test-rooms and the anteroom) and (b) view into one of the two offices at the LOBSTER which demonstrates the positions of the participants in respect to the front walls (artificial windows) and the position of sensors.

Figure 4 presents the timeline for daily experiments. After arrival, the participants were requested to have a seat the anteroom for acclimation, introduction of experiments, attachment of sensors and filling the daily background questionnaires. Participants were requested to keep the winter cloth (corresponding approximately $1.0 \mathrm{clo}$ ) and to not drink and eat during the experiments. Learning from our pilot study and former studies [23,24], the period of 15-30 min can be sufficient for acclimation to 
have a stable skin temperature. After $30 \mathrm{~min}$, the four participants were asked to enter the test-rooms, to be sedentary at their positions (Figure $3 b$ ) and to answer the first short questionnaire using the tablets. The 2nd short questionnaire (similar to the 1st questionnaire) popped up at the screen after $15 \mathrm{~min}$ and the last comprehensive questionnaire popped up after $45 \mathrm{~min}$. During the experiments, the subjects' skin temperature at eight body positions suggested by EN-ISO 9886 (ISO 9886 2004) and the thermal environmental parameters of the room such as air velocity, air temperature, air humidity and globe temperature at three heights near to the participants and room surface temperatures were measured with the time-resolution of $1 \mathrm{~min}$.

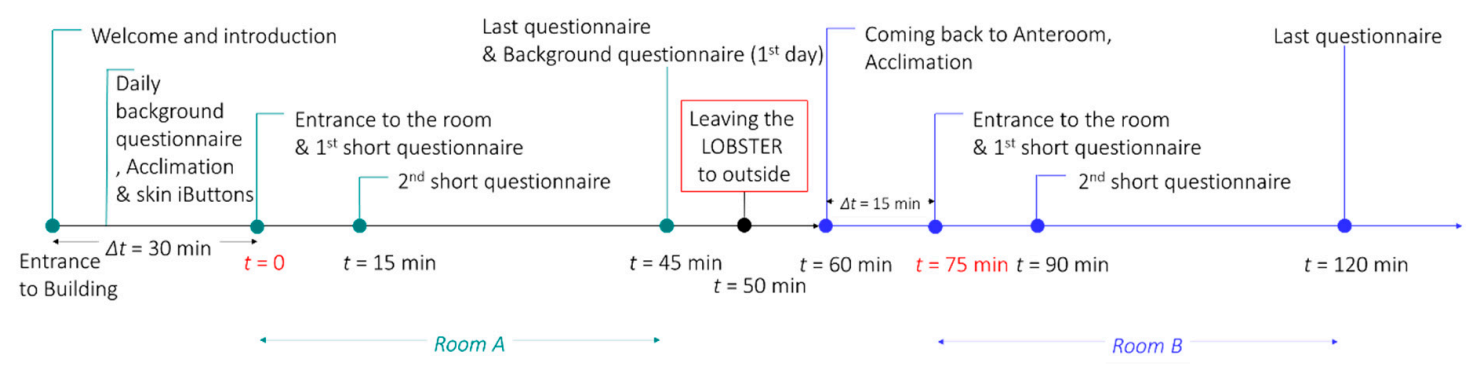

Figure 4. Timeline for experiments and questionnaires.

A within-subject experimental design was chosen, meaning that the same people attended different scenarios in three different weeks. Each week, one ceiling surface temperature was tested and each day, four participants each attended the morning and afternoon sessions. In each session, four participants tested both rooms with two different front walls' (artificial window) temperatures according to Figure 4. However, the two participants in each room stayed in the same positions in respect to the front artificial window, so that a group of two participants always sat at the front seat and another group always sat in the back.

The final comfort questionnaire was relatively long and included questions about the overall and local thermal sensation, overall and local thermal comfort, thermal sensation preference, humidity acceptance and preference, air quality, perceived room air temperature, asymmetric body temperature, and thermal satisfaction. However, in this paper, we focused on the analyses of subjective thermal sensation and comfort votes, thermal asymmetry and thermal satisfaction. Table 2 presents comfort scales about thermal sensation (ASHRAE 7-point scale) and thermal comfort (4-point scale). The 10 body parts were selected based on the suggested 8 body points proposed by EN-ISO 9886 and an additional two positions including right foot and top of the head. The suggested 8 points are the forehead, right scapula, left upper chest, right upper arm in upper location, left lower arm in upper location, left hand and left calf. Since the side walls in the rooms had about identical temperatures $\left(20^{\circ} \mathrm{C}\right)$ and the participants were positioned in equal distances to the side walls, it is assumed that symmetric conditions in terms of skin temperatures and body thermal status between the right and left sides of the body was established.

Table 2. Comfort scales used in the experiments. TSV and TCV denote thermal sensation and thermal comfort votes.

\begin{tabular}{cccc}
\hline TSV & \multicolumn{2}{c}{ TCV } \\
\hline Label & Value & Label & Value \\
\hline Hot & +3 & Comfortable & +3 \\
Warm & +2 & Just comfortable & +2 \\
Slightly warm & +1 & Just uncomfortable & +1 \\
Neutral & 0 & Uncomfortable & 0 \\
Slightly cool & -1 & - & - \\
Cool & -2 & - & - \\
Cold & -3 & - & - \\
\hline
\end{tabular}


The experimental design and procedures were approved by the ethical and data protection committees. Additionally, informed consent was signed by the participants prior to their participation in the first day.

\subsection{Measurements}

Thermal environmental parameters including the air temperature, air humidity, air velocity, and the globe temperatures were measured with the time-resolution of $1 \mathrm{~min}$ near to the occupants at three different heights of 10, 60 and $110 \mathrm{~cm}$. These heights include the occupant zone for a sedentary person [7]. The radiant and operative temperature were calculated based on the measured globe and air temperatures using the R-package "comf" [25]. Table 3 presents the mean values and standard deviations of measured indoor environmental parameters in six different cases at two positions at the height of $110 \mathrm{~cm}$ as exemplary results. It should be noted that although the PMV is not suggested for non-uniform and asymmetry conditions, it is presented here to estimate the created thermal conditions by the warm ceiling. As presented in Table 3, according to the PMV calculations, the room thermal condition was about "neutral" for a sedentary person having winter clothing. Figure 5 shows the instruments and the positions of sensors near the occupants. An indirect method based on view factors and room surface temperatures [26] was also used for calculation of mean radiant temperatures in asymmetric conditions.

Table 3. Mean values and standard deviations (mean $\pm \mathrm{sd}$ ) of the measured indoor environmental parameters at the height of $110 \mathrm{~cm}$. CT stands for the ceiling temperature.

\begin{tabular}{|c|c|c|c|c|c|c|c|c|c|}
\hline \multicolumn{3}{|c|}{ Scenarios } & \multirow{2}{*}{$\frac{\text { Scenario No. }}{\text { S1 }}$} & \multirow{2}{*}{$\frac{\operatorname{Tair}\left({ }^{\circ} \mathbf{C}\right)}{20.6 \pm 0.5}$} & \multirow{2}{*}{$\frac{\operatorname{Top}\left({ }^{\circ} \mathrm{C}\right)}{20.6 \pm 0.5}$} & \multirow{2}{*}{$\begin{array}{c}T_{r}\left({ }^{\circ} \mathbf{C}\right) \\
20.7 \pm 0.5\end{array}$} & \multirow{2}{*}{$\begin{array}{c}V_{\text {air }}(\mathbf{m} / \mathbf{s}) \\
0.03 \pm 0.01\end{array}$} & \multirow{2}{*}{$\begin{array}{c}\text { RH (\%) } \\
34.2 \pm 3.5\end{array}$} & \multirow{2}{*}{$\begin{array}{r}\text { PMV } \\
-0.7\end{array}$} \\
\hline \multirow{6}{*}{$\begin{array}{l}3 \\
0 \\
0 \\
0 \\
0 \\
3 \\
0 \\
0 \\
0\end{array}$} & & CT: $28^{\circ} \mathrm{C}$ & & & & & & & \\
\hline & Front ${ }^{1}$ & CT: $33{ }^{\circ} \mathrm{C}$ & $\mathrm{S} 2$ & $21.2 \pm 0.6$ & $21.4 \pm 0.8$ & $21.6 \pm 0.9$ & $0.04 \pm 0.01$ & $33.9 \pm 3.9$ & -0.5 \\
\hline & & $\mathrm{CT}: 38^{\circ} \mathrm{C}$ & S3 & $22.1 \pm 0.8$ & $22.2 \pm 0.8$ & $22.3 \pm 0.7$ & $0.02 \pm 0.01$ & $32.9 \pm 3.3$ & -0.3 \\
\hline & & CT: $28^{\circ} \mathrm{C}$ & $\mathrm{S} 4$ & $20.8 \pm 0.5$ & $21.0 \pm 0.5$ & $21.3 \pm 0.4$ & $0.06 \pm 0.01$ & $31.2 \pm 3.2$ & -0.6 \\
\hline & Rear $^{2}$ & CT: $33^{\circ} \mathrm{C}$ & S5 & $22.1 \pm 0.5$ & $22.4 \pm 0.5$ & $22.6 \pm 0.6$ & $0.07 \pm 0.02$ & $30.7 \pm 3.8$ & -0.3 \\
\hline & & $\mathrm{CT}: 38^{\circ} \mathrm{C}$ & S6 & $22.4 \pm 0.7$ & $22.5 \pm 0.6$ & $22.5 \pm 0.6$ & $0.05 \pm 0.01$ & $31.0 \pm 3.0$ & -0.2 \\
\hline \multirow{6}{*}{ 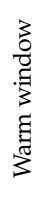 } & & CT: $28^{\circ} \mathrm{C}$ & S7 & $21.2 \pm 1.1$ & $21.3 \pm 1.1$ & $21.4 \pm 1.1$ & $0.03 \pm 0.01$ & $30.1 \pm 2.5$ & -0.5 \\
\hline & Front ${ }^{3}$ & CT: $33^{\circ} \mathrm{C}$ & S8 & $21.4 \pm 1.1$ & $21.5 \pm 1.0$ & $21.6 \pm 1.2$ & $0.04 \pm 0.01$ & $31.0 \pm 3.8$ & -0.5 \\
\hline & & $\mathrm{CT}: 38^{\circ} \mathrm{C}$ & S9 & $22.2 \pm 1.1$ & $22.3 \pm 1.4$ & $22.4 \pm 1.4$ & $0.03 \pm 0.01$ & $33.2 \pm 5.0$ & -0.3 \\
\hline & & CT: $28^{\circ} \mathrm{C}$ & S10 & $21.4 \pm 0.7$ & $21.7 \pm 0.7$ & $21.9 \pm 0.7$ & $0.05 \pm 0.01$ & $27.4 \pm 2.1$ & -0.5 \\
\hline & Rear $^{4}$ & CT: $33^{\circ} \mathrm{C}$ & S11 & $22.2 \pm 0.5$ & $22.4 \pm 0.5$ & $22.7 \pm 0.6$ & $0.06 \pm 0.02$ & $27.8 \pm 3.7$ & -0.3 \\
\hline & & $\mathrm{CT}: 38^{\circ} \mathrm{C}$ & $\mathrm{S} 12$ & $23.7 \pm 0.8$ & $23.3 \pm 0.8$ & $23.0 \pm 0.8$ & $0.06 \pm 0.01$ & $30.4 \pm 2.5$ & 0.0 \\
\hline
\end{tabular}

${ }^{1} 1$ st group-scenario; ${ }^{2}$ 2nd group-scenario; ${ }^{3} 3$ rd group-scenario; ${ }^{4} 4$ th group-scenario.

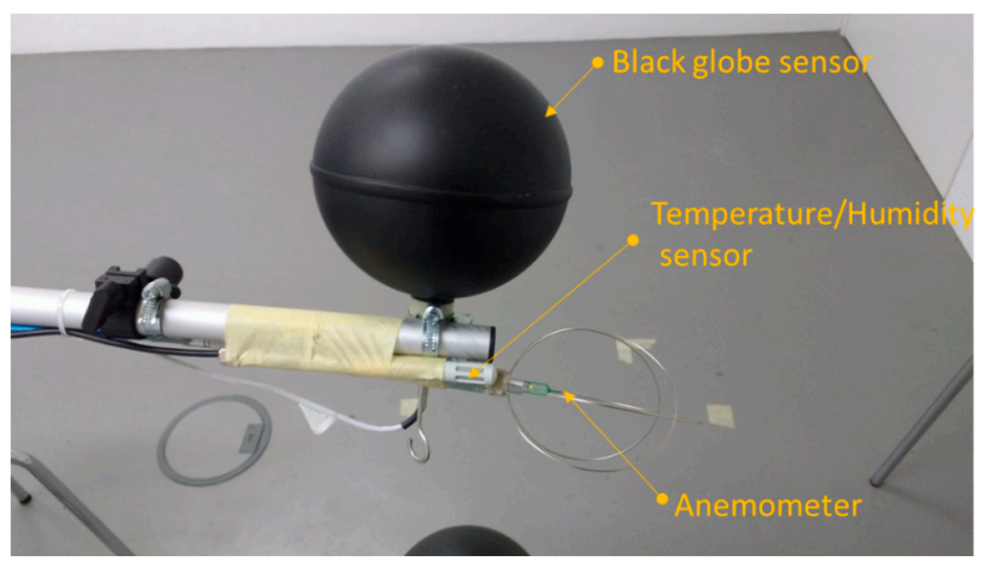

(a)

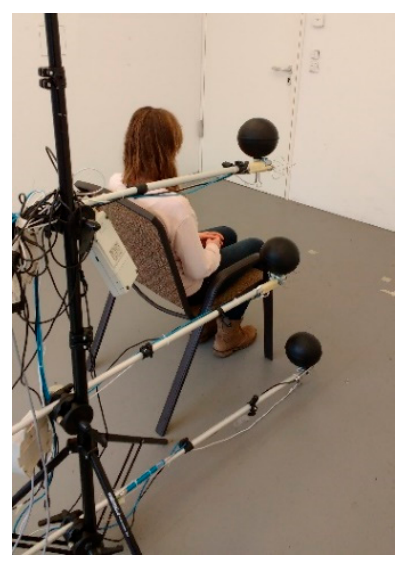

(b)

Figure 5. (a) Sensors (air temperature/humidity, air velocity, and globe temperature) and (b) their positions at 10,60 and $110 \mathrm{~cm}$ from the floor. 


\subsection{Statical Analyses}

The non-parametric Friedman ANOVA test was used to test differences in subjective responses between different scenarios. If the null-hypothesis at each set of scenarios is rejected for a $p$-value of 0.05 , the differences between each pair of scenarios were evaluated by the Wilcoxon signed-rank test. The statistical analyses were performed using the R-package "stats" [27].

\section{Experimental Results and Discussion}

\subsection{Thermal Sensation Analysis}

The percentages of overall thermal sensation votes (TSVs), not the local votes, in response to the twelve scenarios (given in Table 3) are shown in Figure 6. In all but scenario S1, the majority of overall TSVs lay between "slightly cool, -1 " and "slightly warm, +1 ", reaching more than $84 \%$ for three scenarios related to the ceiling surface temperatures set to $33^{\circ} \mathrm{C}$. Most of the participants voted between "slightly cool, -1 " and "cold, -3 " in the scenarios, where the ceiling surface temperature was set to $28^{\circ} \mathrm{C}$ (S1, S4, S7, S10). Such voting behavior is most prominent for the scenario with the distance of $1 \mathrm{~m}$ to the cool artificial window (1st), where more than $80 \%$ voted as such and less than $40 \%$ voted between "slightly cool, -1 " and "slightly warm, +1 ". In contrast to the ceiling surface temperatures of 28 and $33^{\circ} \mathrm{C}$, more participants responded "slightly warm" as well as "warm" in all four scenarios (S3, $\mathrm{S6}, \mathrm{S} 9$, and S12) with the radiant ceiling operating at $38^{\circ} \mathrm{C}$, and it is most apparent for the scenario with warm window (S9 and S12).

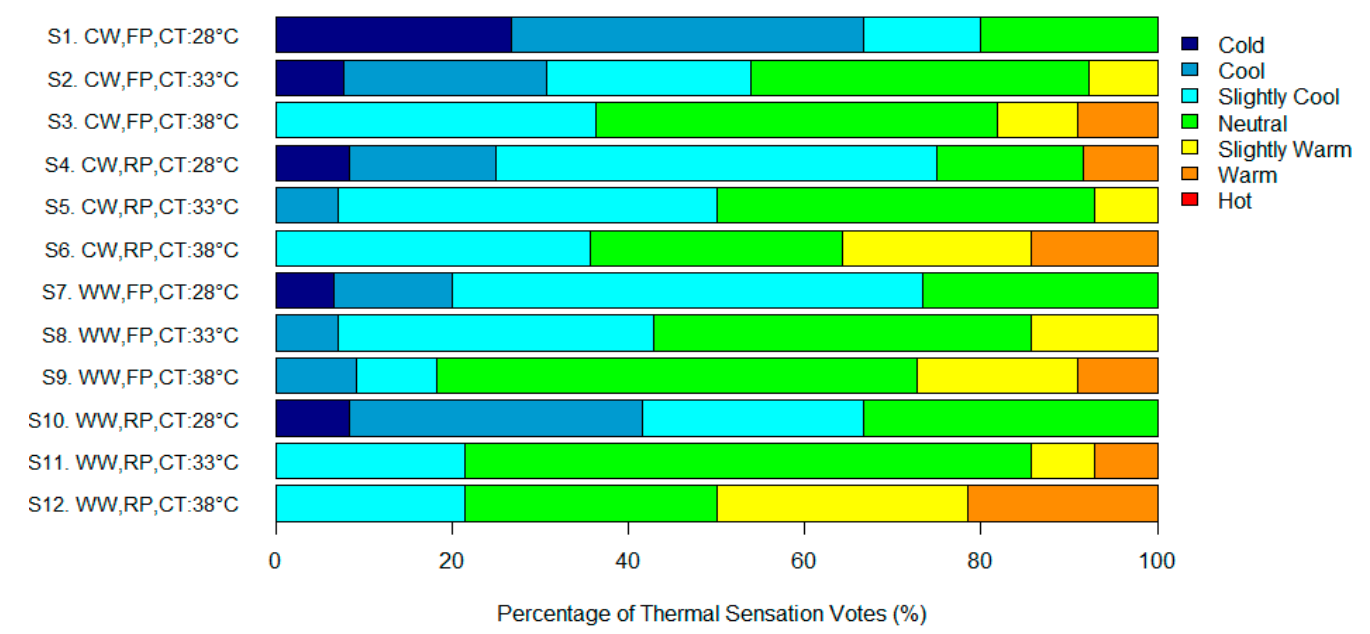

Figure 6. Percentage of overall thermal sensation votes divided into 7 scales, from cold to warm, in response to 12 different experimental scenarios. S1-S12 are the twelve scenarios presented in Figure 2 and Table 3. CW and WW denote cool and warm window; FP and RP stand for the front and rear positions; and $\mathrm{CT}$ is the ceiling surface temperature.

In reality, the temperature of the window is strongly associated with the window type and thereby especially its U-value. Comparing the distribution of overall TSVs shown in Figure 6 between the scenarios with cold window (S1-S6) and warm window (S7-S12) with each other, i.e., S1 with S7, S2, with S8, and so on, the temperature of the window had the highest influence on overall TSVs when the ceiling surface temperature was set to $28^{\circ} \mathrm{C}$. The window temperature's impact on the votes in the scenarios with the ceiling surface temperature of $33^{\circ} \mathrm{C}$ was slightly lower, but it is still noticeable, particularly at the positions near to the window (FP: S1-S3, S7-S9). The impact of the window temperature was minimum when the ceiling surface temperature was set to $38^{\circ} \mathrm{C}$.

Additionally, concerning the distance to the artificial window, the comparison among the scenarios shows that the participants sitting in the front felt cooler than the other group sitting in the rear when having other factors fixed. However, this comparison needs to be done with cautiousness, because the 
participants who sat near to the artificial façade were different from the participants who sat at the rear positions.

Figure 7 presents the averages of overall and local thermal sensation votes in each scenario (listed in Table 3). The four plots are separated based on the thermal status of artificial windows (warm and cool) and the positions of participants (front and rear positions). Each plot contains the overall and local thermal sensation votes acquired at different ceiling surface temperatures $\left(28,33,38^{\circ} \mathrm{C}\right)$. According to the PMV calculations presented in Table 3, the overall thermal condition is within a narrow range between "slightly cool" and "neutral". Therefore, it can be assumed that the observed differences between local thermal sensation can be attributed mainly to differences in the radiant temperature asymmetry and not to those of the overall thermal environmental parameters.

Figure 7 shows that, in general, the overall and local sensation had the highest values in the scenarios when the ceiling surface temperature was set to $38^{\circ} \mathrm{C}$ (red lines), especially at the scenario with warm window and rear position. The lowest votes occurred at the ceiling surface temperature of $28^{\circ} \mathrm{C}$ (blue lines), especially for the scenario with the distance of $1 \mathrm{~m}$ to the cool artificial window.

In these four plots shown in Figure $7 \mathrm{a}-\mathrm{d}$, the average overall TSVs for the scenarios with the ceiling surface temperature of $28^{\circ} \mathrm{C}$ (blue lines) are in the cold zone [ -2.0 and -1.0]. At the ceiling surface temperature of $28^{\circ} \mathrm{C}$, the average values of votes at the upper-body parts (except hand and forearm) lay between "slightly cool, -1 " and "neutral, 0 ", and the votes at the lower parts (except thigh) are between "cold, -2 " and "slightly cool, -1 ". At this ceiling temperature, the temperature of the window/façade, corresponding to the type of window/façade, influenced the participants' votes slightly, and it has the minimum impact at the parts that are cool/cold. At the ceiling temperature of $28^{\circ} \mathrm{C}$ as well as other temperatures, the head and forehead have the highest average value of votes compared to the other limbs which are about "neutral". The coldest parts are the feet and then hands.

At the ceiling temperature of $33^{\circ} \mathrm{C}$, in general, the average of votes at the majority of body parts except for the cold extremities (feet and hands) is about "neutral". The participants voted local feet and hands between "slightly cool, -1 " and "neutral, 0 " for the four group-scenarios (Figure 7a-d). Forehead and head were slightly warmer than the other upper limbs, and the feet and the hands are the coolest limbs. The temperature of the window at the ceiling temperature of $38^{\circ} \mathrm{C}$ had a minimum impact on the global and local TSVs for both positions. At this temperature, the temperature of the window slightly influenced the local thermal sensations votes at cool body parts for the participants who sat in the front positions (Figure 7a,c), and its influence at the participants' perception who sat the front positions was weak. In general, the global and local thermal sensation votes (except feet and hands) related to the ceiling temperature of $38^{\circ} \mathrm{C}$ lay between "neutral, 0 " and "slightly warm, +1 ". At this ceiling temperature, averages of votes at cold extremities (feet and hands) were between "slightly cool, -1 " and "neutral, 0 ", and the warmest votes at these limbs occurred for the 12th scenario shown in Figure $7 \mathrm{~d}$.

Comparison among these scenarios indicates that although the radiant ceiling at the temperature $38^{\circ} \mathrm{C}$ provides about "neutral" conditions at majority of body parts even at extremities, the ceiling temperature of $33{ }^{\circ} \mathrm{C}$ can provide fairly "neutral" conditions at majority of body parts (except extremities) if the temperature of the envelope is relatively high (e.g., $20^{\circ} \mathrm{C}$ ). Such conditions occur, e.g., when standard building envelopes with relatively low $\mathrm{U}$-values are applied. 


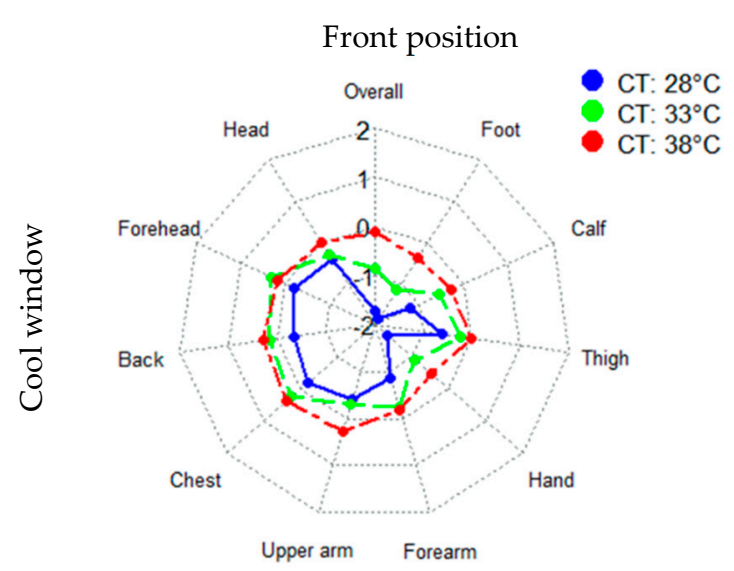

(a)

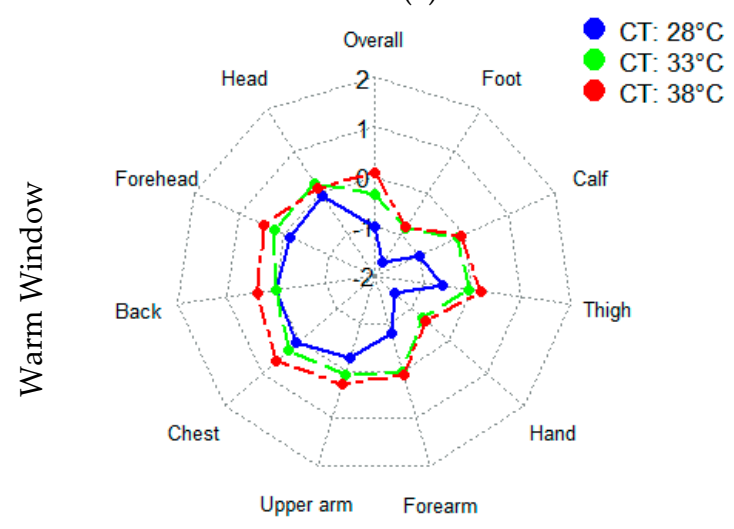

(c)

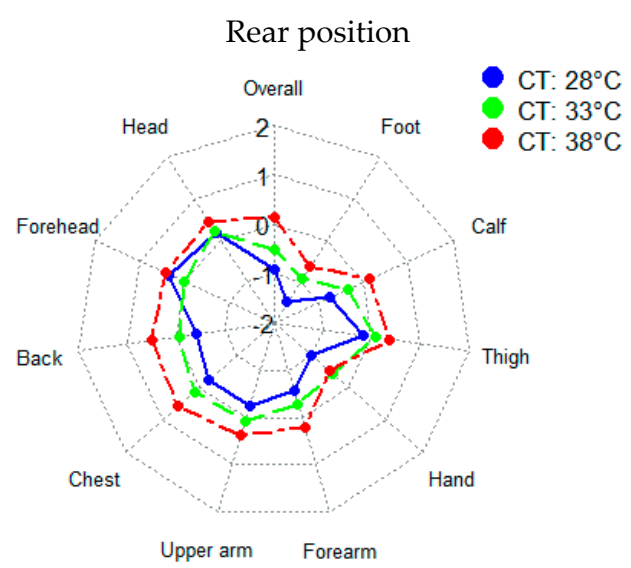

(b)

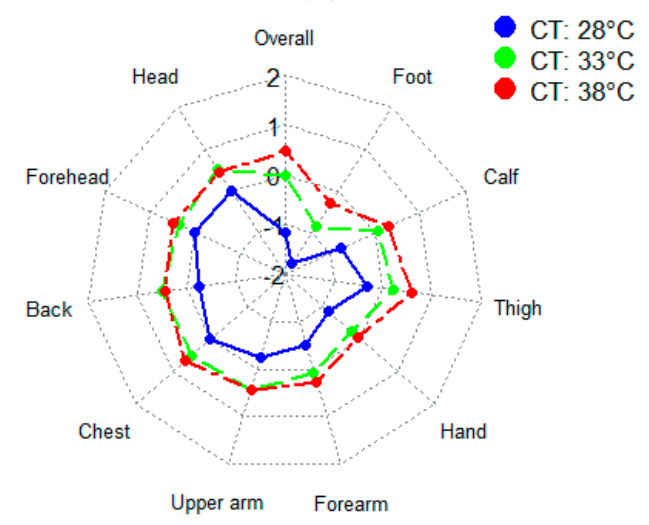

(d)

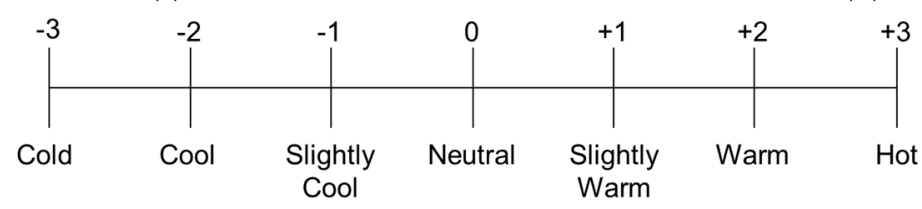

(e)

Figure 7. Average of overall/local thermal sensation votes in 12 different experimental scenarios. A combination of scenarios is presented in Figure 3 and Table 3. (a) Scenario group-1 related to the cool window and the front position; (b) Scenario group-2 related to the cool window and the rear position; (c) Scenario group-3 related to the cool window and the rear position; (d) Scenario group-4 related to the warm window and the rear position; (e) ASHRAE 7-point thermal sensation scale.

Table 4 presents the p-values derived from the non-parametric Friedman ANOVA test. For this test, four scenario groups were created, distinguished by the distance to the window (DW: $1 \mathrm{~m}$ (FP) or $3 \mathrm{~m} \mathrm{(RP))} \mathrm{and} \mathrm{the} \mathrm{window} \mathrm{temperature} \mathrm{(WT:} 15.5^{\circ} \mathrm{C}$ (cool) or $19^{\circ} \mathrm{C}$ (warm)). Note that these groups relate to the four sub-figures of Figure 7, e.g., scenario group-1 relates to Figure 7a. In this test, the ceiling temperature is the independent variable and the null hypothesis states that there is no significant difference in thermal sensation votes for the three ceiling temperatures $(28,33$ and $38^{\circ} \mathrm{C}$ ) at each scenario group. As seen in Table 4, there is a significant difference between the ceiling temperatures for overall thermal sensation at three of four group-scenarios. 
Table 4. Non-parametric Friedman ANOVA test. WT and DW stand for the window temperature and distance to the window, respectively.

\begin{tabular}{|c|c|c|c|c|}
\hline $\begin{array}{l}\text { Thermal Sensation } \\
\text { (Body Parts) }\end{array}$ & $\begin{array}{c}\text { Scenario Group-1 } \\
\left.\text { (DW: } 1 \mathrm{~m} \text {; WT: } 15.5^{\circ} \mathrm{C}\right)\end{array}$ & $\begin{array}{l}\text { Scenario Group-2 (DW: } \\
\left.3 \mathrm{~m} \text {; WT: } 15.5^{\circ} \mathrm{C}\right)\end{array}$ & $\begin{array}{c}\text { Scenario Group-3 } \\
\left.\text { (DW: } 1 \mathrm{~m} \text {; WT: } 19^{\circ} \mathrm{C}\right)\end{array}$ & $\begin{array}{l}\text { Scenario Group-4 } \\
\left.\text { (DW: } 3 \mathrm{~m} ; \mathrm{WT}: 19^{\circ} \mathrm{C}\right)\end{array}$ \\
\hline Overall & $0.003 *$ & $0.013 *$ & 0.053 & $0.004 *$ \\
\hline Head & 0.280 & 0.273 & 0.676 & 0.148 \\
\hline Forehead & 0.368 & 0.062 & 0.852 & 0.091 \\
\hline Back & 0.834 & $0.042 *$ & 0.902 & 0.247 \\
\hline Chest & 0.417 & $0.008 *$ & 0.459 & 0.074 \\
\hline Upper arm & 0.121 & 0.497 & 0.485 & 0.091 \\
\hline Forearm & 0.895 & 0.030 * & 0.114 & 0.065 \\
\hline Hand & 0.072 & 0.682 & 0.256 & $0.021 *$ \\
\hline Thigh & 0.792 & 0.417 & 0.396 & $0.009 *$ \\
\hline Calf & 0.353 & 0.102 & 0.192 & $0.039 *$ \\
\hline Foot & $0.023 *$ & $0.041 *$ & 0.401 & 0.004 * \\
\hline
\end{tabular}

* Significant difference $(p<0.05)$.

Table 5 presents the results of the Wilcoxon signed rank test to determine the statistical significance of the difference between each pair of ceiling temperatures. The results indicate that there is a significant difference between the ceiling temperatures of $28{ }^{\circ} \mathrm{C}$ and $38^{\circ} \mathrm{C}$ for all 4 group-scenarios. It means that the overall thermal sensation votes are significantly different at the ceiling temperatures of $28^{\circ} \mathrm{C}$ and $38^{\circ} \mathrm{C}$, while overall calculated PMV values (see Table 3 ) are very close to each other.

Table 5. Results from the Wilcoxon signed rank test for the overall thermal sensation at four scenario groups given in Table 4. WT and DW stand for the window temperature and distance to the window, respectively.

\begin{tabular}{|c|c|c|c|c|c|c|c|c|}
\hline \multirow{2}{*}{$\begin{array}{c}\text { Ceiling } \\
\text { Temperatures }\end{array}$} & \multicolumn{2}{|c|}{$\begin{array}{c}\text { Scenario Group-1 } \\
\left.\text { (DW: } 1 \mathrm{~m} ; \mathrm{WT}: 15.5^{\circ} \mathrm{C}\right)\end{array}$} & \multicolumn{2}{|c|}{$\begin{array}{c}\text { Scenario Group-2 } \\
\left.\text { (DW: } 3 \mathrm{~m} ; \mathrm{WT}: 15.5^{\circ} \mathrm{C}\right)\end{array}$} & \multicolumn{2}{|c|}{$\begin{array}{l}\text { Scenario Group-3 } \\
\left.\text { (DW: } 1 \mathrm{~m} ; \mathrm{WT}: 19^{\circ} \mathrm{C}\right)\end{array}$} & \multicolumn{2}{|c|}{$\begin{array}{l}\text { Scenario Group-4 } \\
\left.\text { (DW: } 3 \text { m; WT: } 19^{\circ} \mathrm{C}\right)\end{array}$} \\
\hline & $\mathrm{CT}: 28^{\circ} \mathrm{C}$ & $\mathrm{CT}: 33^{\circ} \mathrm{C}$ & $\mathrm{CT}: 28^{\circ} \mathrm{C}$ & $\mathrm{CT}: 33^{\circ} \mathrm{C}$ & $\mathrm{CT}: 28{ }^{\circ} \mathrm{C}$ & $\mathrm{CT}: 33{ }^{\circ} \mathrm{C}$ & $\mathrm{CT}: 28^{\circ} \mathrm{C}$ & $\mathrm{CT}: 33{ }^{\circ} \mathrm{C}$ \\
\hline $\mathrm{CT}: 38^{\circ} \mathrm{C}$ & $0.010 *$ & 0.084 & $0.014 *$ & $0.038 *$ & $0.031 *$ & 0.160 & $0.010^{*}$ & 0.414 \\
\hline
\end{tabular}

* Significant difference $(p<0.05)$.

At the same time, in the 2nd and 3rd scenario groups, there is no significant difference in thermal sensation votes between the ceiling temperatures of $28{ }^{\circ} \mathrm{C}$ and $33^{\circ} \mathrm{C}$. Moreover, the influence of rising the ceiling temperature from $33{ }^{\circ} \mathrm{C}$ to $38^{\circ} \mathrm{C}$ on the overall thermal sensation votes is insignificant for all scenario groups except the 2 nd.

Additionally, the results of the Friedman test presented in Table 4 indicate that, in general, the difference in thermal sensation votes between the ceiling temperatures is insignificant for the majority of body parts in four group-scenarios, particularly the first 3 group-scenarios.

The analysis of data for local thermal sensation votes indicates that although, according to the Freidman test, there is no significant difference between some scenarios, the averages of local thermal sensation votes shown in Figure 7 varied from one scenario to another. There are some possible reasons to explain these findings: (i) the body limbs, particularly clothed limbs and non-extremities, were not sensitive to the changes of radiative room surfaces and slight changes of room air temperature [28]. These findings are in contrast with other results related to local thermal sensation and comfort done by Zhang et al. in which the averages of local thermal sensation votes strongly depend on the experimental conditions $[23,24]$. They observed the significant reaction of the local body limbs to the changes of surrounding air conditions, and the local thermal sensation votes were selected as significant parameters to predict the overall thermal sensation. This contrast between the two studies may be explained by the fact that heat exchange between the local body surface and the surrounding thermal environment was only through the convection in their study, while in our experiments both radiation and convection occurred. The second reason (ii) for the insignificant difference between the scenarios might be the type of scale used for the evaluation of local thermal sensation. The thermal sensation scale is symmetrical (from "cold, -3 " over "neutral, 0 " to "hot, +3 ") and the tendency of 
majority of participants to select the central three categories ("slightly cool, -1 " to "slightly warm, $\left.+1^{\prime \prime}\right)$ is high [29-31]. Consequently, the median values of votes related to different experimental conditions are close to each other and within the central three categories (see Figure A1 in Appendix A). The closeness of the median values in different scenarios may result in insignificant differences between the median distribution and the hypothetical median. Different types of thermal sensation scales such as visual analogue scales may lead to more pronounced differences between the scenarios, but cannot be compared directly to existing data as discussed earlier [31]. The possible third reason (iii) is that the participants may vote at some body parts based on a reference (extreme) cold or warm body parts. For example, the participants may vote the chest differently if the extremities are cold or hot, even the surrounding thermal conditions around the chest are the same. It may influence the accuracy of local votes.

\subsection{Thermal Comfort Analysis}

Figure 8 presents the percentage of overall thermal comfort votes (TCVs) observed in the twelve different scenarios listed in Table 3. The four scenarios related to the ceiling temperature of $28^{\circ} \mathrm{C}$ (S1, $\mathrm{S} 4, \mathrm{S7}, \mathrm{S10}$ ) had the least percentage of "comfortable" and "just comfortable" votes, particularly the scenario with the cool window and a front position (S1). At this ceiling temperature, the percentage of "comfortable" and "just comfortable" votes was highest if the position of participants was $3 \mathrm{~m}$ away from the artificial window and a warm temperature $\left(19^{\circ} \mathrm{C}\right)$ of the artificial window (S10). At the ceiling temperature of $33^{\circ} \mathrm{C}$, the percentages of "comfortable" were more than the same votes at the ceiling temperature of $38^{\circ} \mathrm{C}$, except for the scenario with warm window and rear position (S11).

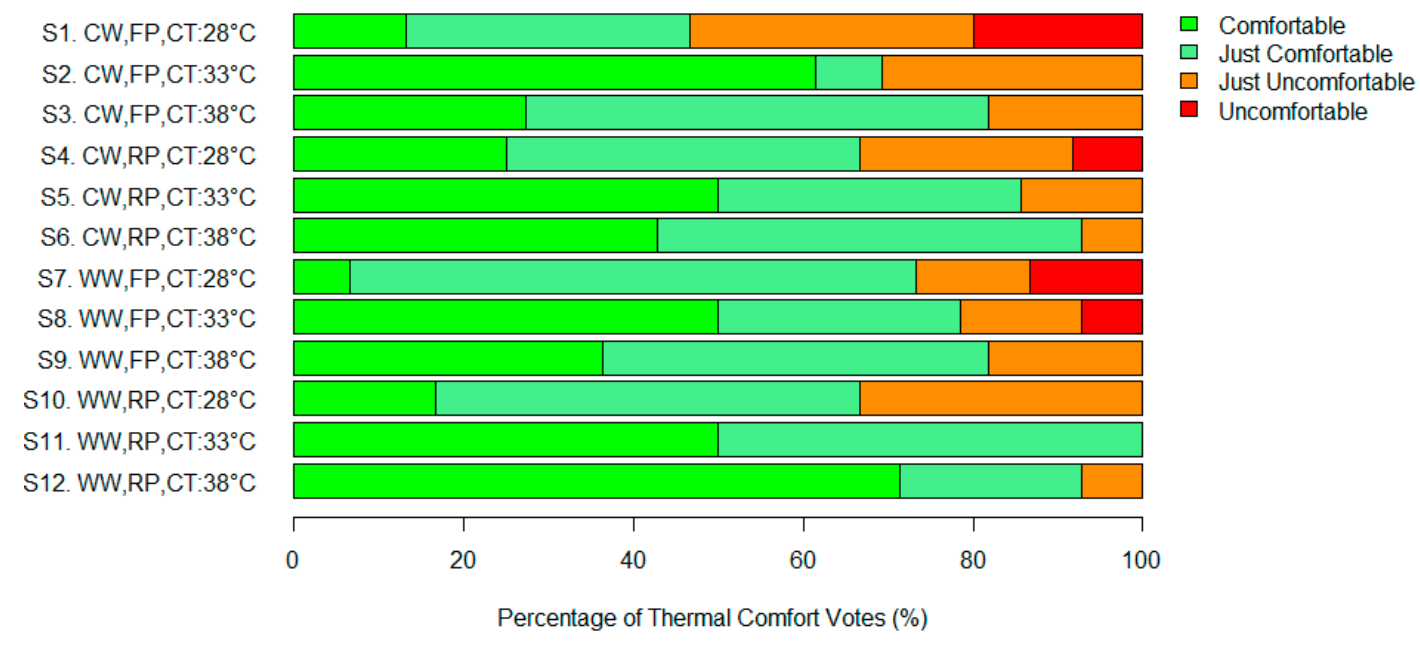

Figure 8. Percentage of overall thermal comfort votes divided into 4 scale points, from "uncomfortable" to "comfortable", in response to 12 different experimental scenarios. S1 to S12 are the twelve scenarios presented in Figure 2 and Table 3. CW and WW denote cool and warm window; FP and RP stand for the front and rear positions; and CT is the ceiling temperature.

At least $50 \%$ of participants voted "comfortable" for the four scenarios related to the ceiling temperature of $33^{\circ} \mathrm{C}$. At this temperature, the position of participants and the temperature of the window slightly influenced the "comfortable" votes but their effects were notable for "just comfortable" and "just uncomfortable" votes. In contrast, at the ceiling temperature of $38^{\circ} \mathrm{C}$, the "comfortable", "just comfortable" and "just uncomfortable" votes were influenced noticeably by the position of participants and the temperature of the window (differences between S3 and S6, and between S9 and S12). Participants felt more comfortable if they sat in a rear position and in a room with a warm window (S12). The results presented in Figures 8 and 9 clearly indicate that radiant heating ceiling systems operating with the temperatures of $33^{\circ} \mathrm{C}$ and $38^{\circ} \mathrm{C}$ have about equal influence on the overall 
thermal comfort of occupants having least "just comfortable" conditions. The comfort conditions can slightly be improved if the temperature (thermal performance) of the window/façade is increased.

Figure 9 presents the average of overall and local thermal comfort votes (TCVs) at 10 body parts associated with each scenario. Similar to Figure 7, this figure shows four groups of scenarios related to the temperature of the artificial window and the position of participants.

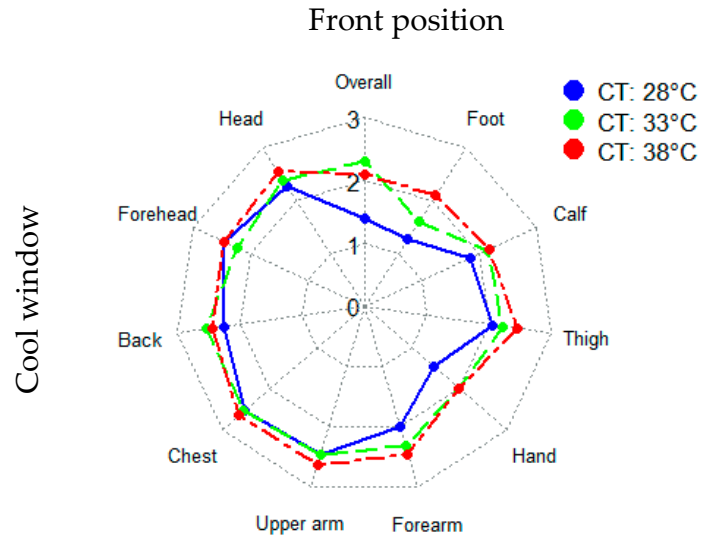

(a)

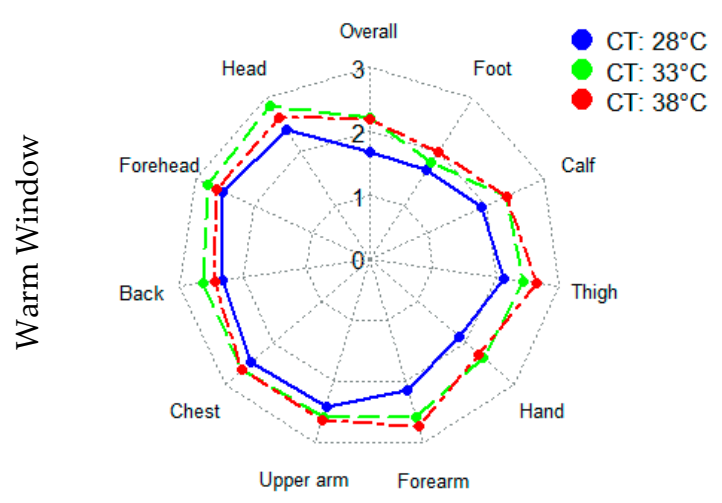

(c)

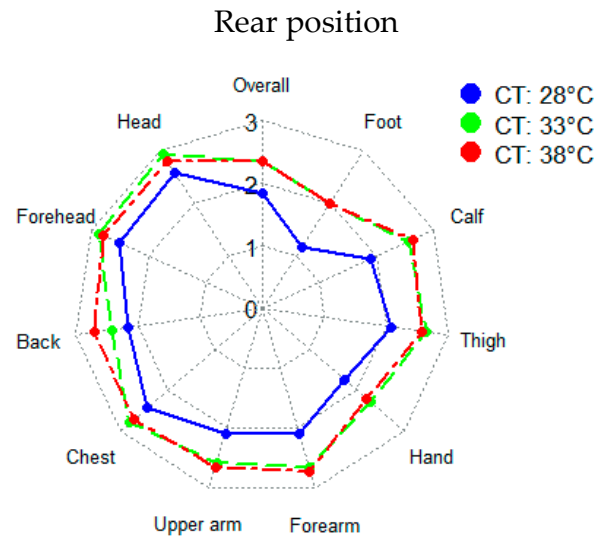

(b)

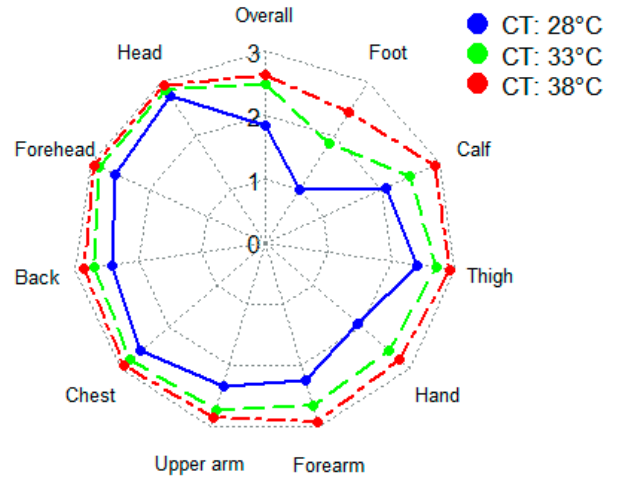

(d)

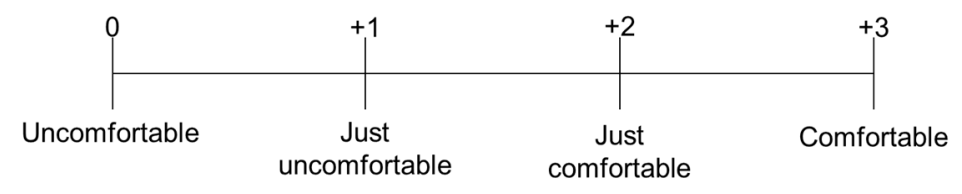

(e)

Figure 9. Average of overall/local thermal comfort votes in 12 different experimental scenarios. A combination of scenarios is presented in Figure 2 and Table 3. (a) Scenario group-1 related to the cool window and the front position; (b) Scenario group-2 related to the cool window and the rear position; (c) Scenario group-3 related to the cool window and the rear position; (d) Scenario group-4 related to the warm window and the rear position; (e) 4-point thermal comfort scale.

Each scenario group consists of the corresponding scenarios distinguished by three ceiling temperatures. As seen from the four plots, the body parts excluding the hand, calf, and feet were voted close to "just comfortable, +2 " at the ceiling temperature of $28^{\circ} \mathrm{C}$. At this ceiling temperature, the extremities and the calf were on average voted between "just uncomfortable, +1 " and "just comfortable, +2 ". Similar to the overall thermal comfort votes, the averages of local thermal votes in response to the ceiling temperatures 33 and $38^{\circ} \mathrm{C}$ are about similar. At the ceiling temperatures of 33 and $38^{\circ} \mathrm{C}$, it is quite unexpected to see that thermal comfort votes of the lower limbs (except foot and hand) have a similar average like the upper limbs, particularly if the artificial window 
temperature was $19^{\circ} \mathrm{C}$. The ceiling temperature of $38^{\circ} \mathrm{C}$ provided conditions perceived as slightly more comfortable at all body limbs compared to a ceiling temperature of $33^{\circ} \mathrm{C}$ and lead to a "comfortable, +3 " vote at all body parts only if the 4 th group-scenario took place. The results imply that improving thermal performance of the window has a positive influence in providing thermal comfort conditions for occupants.

Friedman test results indicate that there is a significant difference between the three ceiling temperature for scenario group $1(p=0.05)$ and $4(p=0.008)$. The changes in ceiling temperature have a significant influence on few limbs including the back in the 1st scenario group (related to Figure 9a), foot in the 2nd scenario group, and hand, thigh, calf, and foot in 4 th scenario group $(p<0.04)$. The Wilcoxon signed rank test was performed for the aforementioned scenario groups to determine whether there is a significant difference in thermal comfort votes between each pair of ceiling temperatures. The test indicates that there is a significant difference between the ceiling temperatures of $28^{\circ} \mathrm{C}$ and 38 ${ }^{\circ} \mathrm{C}$ for all cases. There is a significant difference between $28^{\circ} \mathrm{C}$ and $33^{\circ} \mathrm{C}$ for the two overall thermal comfort votes $(p<0.04)$; however, the test suggested no significant differences between the $28^{\circ} \mathrm{C}$ and $33^{\circ} \mathrm{C}$ as well as $33^{\circ} \mathrm{C}$ and $38^{\circ} \mathrm{C}$ for the aforementioned limbs.

\subsection{Thermal Sensation Asymmetry}

Few studies revealed that radiant heating ceiling systems and cool windows are leading to asymmetric thermal environments, which may cause local discomfort at some body parts and reduce the perceived thermal comfort level $[5,8,18,32]$. However, no studies have been found that analyzed the effect of a radiant heating ceiling and a cool window on the perceived local asymmetry between each pair of body parts. In this study, part of the main questionnaire was designed to enable the analysis of thermal asymmetric perception between five pairs of body-parts. These pairs were selected based on 3-D asymmetric analysis including left to right, up to down and front to back sides. The hand is also included in this comparison, because it is a cold extremity and its thermal status influences the overall satisfaction notably. For this question, participants were asked directly "please compare the two limbs in each pair; which of the body-part do you sense cooler?". The participants had the options to choose one of the limbs or "No difference". Table 6 presents the percentage of participants that selected for one of the limbs "cooler" or "no difference" under the 12 scenarios presented in Table 3.

The answer to the pair "Hand-Foot" (two cold extremities) shows that the majority of participants voted foot as the cooler limbs, except for scenario S3. One reason for this general trend can be that the hand receives a higher amount of the warm radiation emitted from the ceiling due to the higher view factor compared to the foot. In addition, the feet exchanged heat at a relatively high rate with the cool floor (set at $20^{\circ} \mathrm{C}$ ) through conduction. There is no clear evidence to show the influence of the window temperature on the sense of asymmetry. However, in general, we can say that increasing the window temperature and increasing the distance of participants to the window reduces the number of votes to the "cooler foot" and moves the votes towards the perception of a cooler hand and no perceived difference. The analysis of votes for the pairs of "Hand-Head" and "Foot-Head" shows that the participants had a clear sense about the cooler limbs, which are hand and foot. The number of "cooler head" votes decreases and transfers to "No difference" and "cooler hand/foot", if the ceiling temperature increases. The temperature of the window and the position of participants did not have a clear influence on the cooler votes for these two pairs. In all scenarios, the chest had a higher percentage of cooler votes. However, the percentage of "No difference" votes increased dramatically for increased ceiling temperature. It shows that the participants were not able to sense asymmetric thermal conditions between the chest and the back at higher ceiling temperatures. A high percentage of votes for the "No difference" for "right-left" sides, and relatively equal percentage of votes for the "cooler right side" and "cooler left side" can imply that thermal conditions on both sides of the participants were symmetric. It is because the sidewall temperatures were about $20^{\circ} \mathrm{C}$ and the participants were in the middle of the room in respect to the sidewalls. Such observation likely changes, in case the window is positioned on one side of a person leading to left-right asymmetric 
conditions. Consequently, the position of participants and the temperature of the artificial window did not have much impact on asymmetric right-left votes.

Table 6. Asymmetric test: percentage (\%) of participants voted perceived cooler body-part compared to its pair in the questionnaire. CT, Front, Rear stand for the ceiling temperature, Front position ( $1 \mathrm{~m}$ to the artificial window) and Rear position ( $3 \mathrm{~m}$ to the artificial window). Ha: Hand, F: Foot, N: No difference, He: Head, B: Back, C: Chest, L: Left and R: Right.

\begin{tabular}{|c|c|c|c|c|c|c|c|c|c|c|c|c|c|c|c|c|c|c|}
\hline & \multirow{2}{*}{\multicolumn{2}{|c|}{ Scenarios }} & & \multicolumn{3}{|c|}{ Hand-Foot } & \multicolumn{3}{|c|}{ Hand-Head } & \multicolumn{3}{|c|}{ Foot-Head } & \multicolumn{3}{|c|}{ Back-Chest } & \multicolumn{3}{|c|}{ Left-Right } \\
\hline & & & & $\mathrm{Ha}$ & F & $\mathbf{N}$ & Ha & $\mathrm{He}$ & $\mathbf{N}$ & F & He & $\mathbf{N}$ & B & C & $\mathbf{N}$ & L & $\mathbf{R}$ & $\mathbf{N}$ \\
\hline \multirow{6}{*}{ 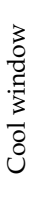 } & \multirow{3}{*}{ Front } & $\mathrm{CT}: 28^{\circ} \mathrm{C}$ & S1 & 33 & 67 & 0 & 80 & 13 & 7 & 80 & 13 & 7 & 33 & 47 & 20 & 20 & 27 & 53 \\
\hline & & CT: $33^{\circ} \mathrm{C}$ & S2 & 15 & 77 & 8 & 69 & 23 & 8 & 85 & 8 & 8 & 15 & 69 & 15 & 8 & 8 & 85 \\
\hline & & $\mathrm{CT}: 38^{\circ} \mathrm{C}$ & S3 & 55 & 36 & 9 & 73 & 9 & 18 & 82 & 0 & 18 & 9 & 27 & 64 & 9 & 18 & 73 \\
\hline & \multirow{3}{*}{ Rear } & $\mathrm{CT}: 28^{\circ} \mathrm{C}$ & S4 & 17 & 75 & 8 & 75 & 17 & 8 & 83 & 8 & 8 & 0 & 50 & 50 & 17 & 17 & 67 \\
\hline & & $\mathrm{CT}: 33^{\circ} \mathrm{C}$ & S5 & 21 & 64 & 14 & 71 & 7 & 21 & 79 & 14 & 7 & 0 & 57 & 43 & 14 & 7 & 79 \\
\hline & & $\mathrm{CT}: 38^{\circ} \mathrm{C}$ & S6 & 14 & 71 & 14 & 79 & 7 & 14 & 93 & 0 & 7 & 7 & 36 & 57 & 0 & 21 & 79 \\
\hline \multirow{6}{*}{ 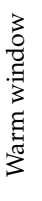 } & \multirow{3}{*}{ Front } & $\mathrm{CT}: 28^{\circ} \mathrm{C}$ & S7 & 47 & 47 & 7 & 87 & 13 & 0 & 73 & 27 & 0 & 27 & 60 & 13 & 20 & 20 & 60 \\
\hline & & $\mathrm{CT}: 33^{\circ} \mathrm{C}$ & S8 & 36 & 64 & 0 & 79 & 14 & 7 & 86 & 14 & 0 & 14 & 71 & 14 & 7 & 21 & 71 \\
\hline & & CT: $38^{\circ} \mathrm{C}$ & S9 & 27 & 45 & 27 & 73 & 0 & 27 & 73 & 0 & 27 & 0 & 27 & 73 & 9 & 18 & 73 \\
\hline & \multirow{3}{*}{ Rear } & $\mathrm{CT}: 28^{\circ} \mathrm{C}$ & S10 & 25 & 58 & 17 & 75 & 17 & 8 & 92 & 8 & 0 & 8 & 42 & 50 & 0 & 25 & 75 \\
\hline & & $\mathrm{CT}: 33^{\circ} \mathrm{C}$ & S11 & 14 & 86 & 0 & 79 & 7 & 14 & 93 & 0 & 7 & 14 & 14 & 71 & 0 & 21 & 79 \\
\hline & & $\mathrm{CT}: 38^{\circ} \mathrm{C}$ & S12 & 36 & 57 & 7 & 79 & 0 & 21 & 86 & 14 & 0 & 0 & 21 & 79 & 7 & 14 & 79 \\
\hline
\end{tabular}

\section{Discussion: Analyses of Comfort Limits}

In contrast to the predicted mean votes, which evaluates uniform thermal conditions based on six thermal environmental and physiological parameters, former systematic studies carried out by Chrenko [3], McNall and Biddison [10], Griffiths and McIntyre [4], and Fanger and Olesen [5] predict the percentage of dissatisfied participants based on "radiant temperature asymmetry". The term "radiant temperature asymmetry" is defined as the difference between the plane radiant temperatures of two opposite sides of a small disk. Fanger [5] proposed the height of $60 \mathrm{~cm}$ from the floor (about the height of the center of a seated person) for calculation of the radiant temperature asymmetry using a horizontal disk. Fanger and his team studied the impact of asymmetric radiation created by a warm ceiling, cool ceiling, cool wall, and warm wall on the percentage of occupants dissatisfied, which is accessible as a guidance in ASHRAE 55-2017 [5,7,8]. This guidance curve recommended a maximum radiant asymmetry temperature of $4 \mathrm{~K}$ for the warm ceiling based on a limit of $5 \%$ dissatisfied.

In a similar way, we analyzed the percentage of dissatisfied participants against the radiant temperature asymmetries in the 12 scenarios (listed in Table 3). For these analyses, three methods were used to assess the percentage dissatisfied (PD). First, the participants were asked directly "Overall, are you satisfied at the moment with the indoor climate?". Answer options were "yes" or "no", leading directly to the observed PD. The second method followed Fanger's recommendation by which the percentage of the dissatisfied occupant was estimated by the percentage of occupants who voted "hot", "warm", "cool" and "cold" [33]. The third method is to calculate the predicted percentage of dissatisfied (PPD) based on the predicted mean vote (PMV) used for the uniform condition [33]. This calculation was done using the R-package "comf" [25]. Although the 3rd method is recommended for uniform conditions, it was used for this comparison. It should be noted that the effect of the cold draft is ignored in our analyses since the air velocity at the three heights is below $0.05 \mathrm{~m} / \mathrm{s}$ (see Table 3).

Based on the first two methods, Figure 10 presents the percentage of dissatisfied participants based on the overall satisfaction question and the overall thermal sensation votes at different radiant temperature asymmetries corresponding different scenarios as well as the guidance curve obtained from Fanger. Figure 11 presents the values of (P)PDs obtained using the aforementioned methods. In general, the figure clearly shows the contradiction between the curves obtained in the present study and Fanger's characteristic curve. Several reasons can explain this inconsistency. As a minor difference, both studies were conducted with different clo values, where the former studies by Fanger were done with a clo value of 0.6 and ours with a clo value of 1.0. 


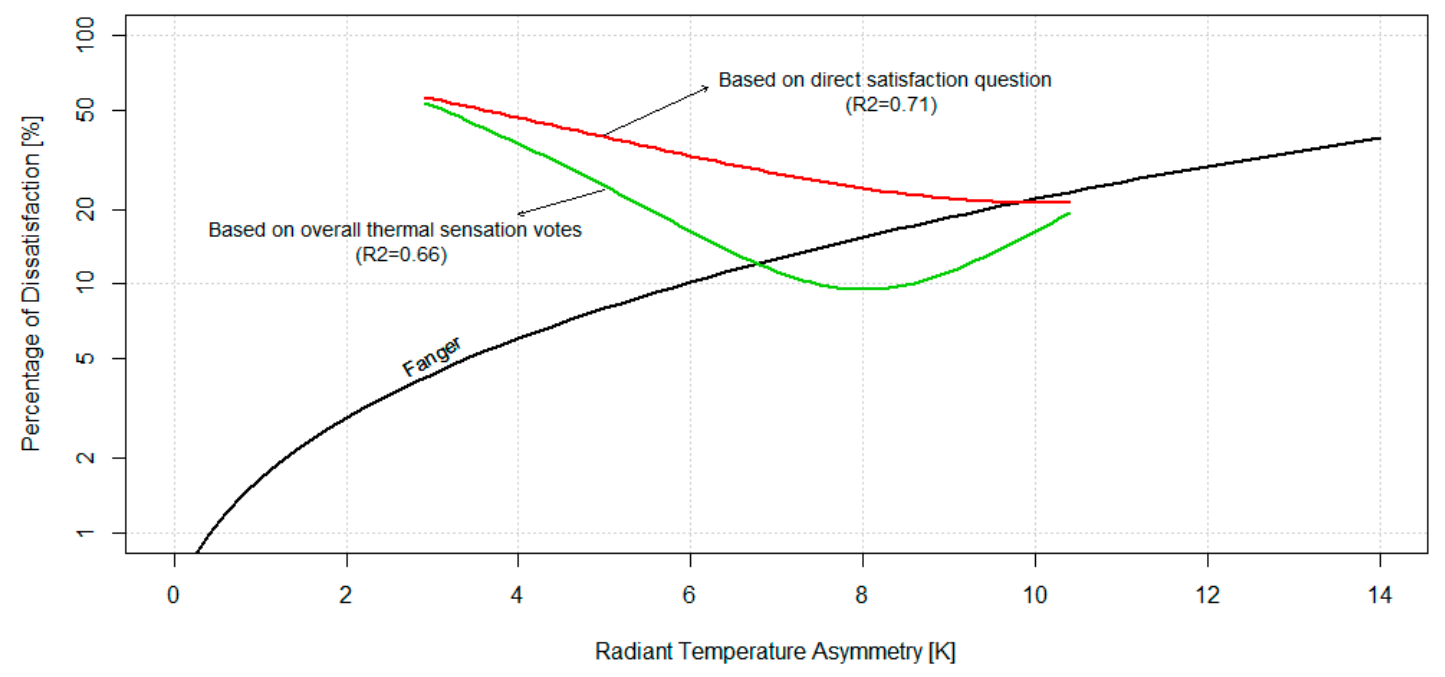

Figure 10. Regression lines comparing two methods of calculating the percentage of dissatisfied participants: (1) direct question about overall satisfaction; (2) assuming thermal sensation votes outside the middle three votes being a statement of dissatisfaction (following Fanger's assumption); and the black reference curve was extracted from guideline curves given by Fanger and ASHRAE-55 [5,7,8].

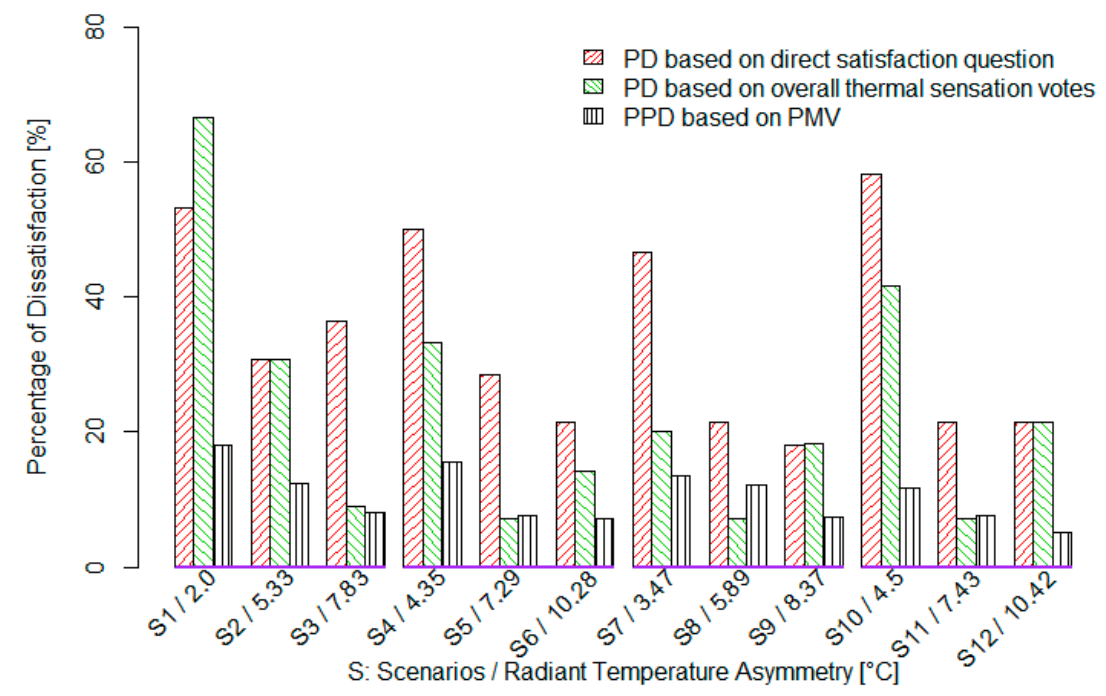

Figure 11. Comparison between the two methods for calculating the percentage of dissatisfied (PD) with respect to different scenarios, and the reference PPD values obtained using PPD-PMV equation given by Fanger and ASHRAE-55 [7,33]. The red bars are based on the direct question about overall satisfaction; whereas, the middle green bars present the PD for the method suggested by Fanger based on the overall thermal sensation votes. S1-S12 are the scenarios stated in Table 3.

The most important reasons for this inconsistency can be found in the experimental design and operating conditions. Fanger's guidance curve was obtained based on experiments in which the operative temperature was kept at about $24^{\circ} \mathrm{C}$ (probably at the height of $60 \mathrm{~cm}$ ), which essentially guarantees thermally neutral conditions for all body parts with summer cloth. In the experiments, th increment of the ceiling temperature was balanced by a reduction of room air and wall temperatures. It was claimed that this method was suitable for simulation of most cases in practice, which may not be true for a dedicated radiant heating ceiling system. In their experiment, the minimum radiant asymmetry temperature (about $0.5^{\circ} \mathrm{C}$ ) happened at the ceiling temperature of $24.1^{\circ} \mathrm{C}$, which was about equal to the room air temperature, the operative temperature, and the wall surface temperatures. Therefore, at this neutral operative temperature, obviously increasing the ceiling temperature and 
consequently the radiant temperature asymmetry increasingly created local discomfort for the occupants, especially at the head which was closest to the warm ceiling.

In contrast, in our experiments, the minimum radiant asymmetry was $2.9 \mathrm{~K}$ (corresponding to the ceiling and window temperatures of 28 and $15.5^{\circ} \mathrm{C}$, respectively), where the high percentage of dissatisfaction due to the cold and uncomfortable extremities was seen (see Figures 7 and 9). As presented in Table 3, although the operative temperature for all scenario was between $20.5^{\circ} \mathrm{C}$ and $23.5^{\circ} \mathrm{C}$ and according to the PMV calculations it was about the neutral thermal condition for a person having winter clothing (clo: 1) [34], the participants voted cool/cold at extremities. Apparently, the local discomfort particularly at extremities for the low radiant surface temperatures noticeably influences the satisfaction of occupants, in which more than $40 \%$ of occupants were dissatisfied with the ceiling temperature of $28{ }^{\circ} \mathrm{C}$. Increasing the ceiling temperature and consequently the radiant temperature asymmetry influenced the PDs obtained by the first two methods differently. As seen from Figure 11, at each of four groups of scenarios (related to ceiling temperatures), the overall percentage of dissatisfaction obtained by the direct satisfaction question was minimum for the ceiling temperature of $38^{\circ} \mathrm{C}$. These results presented in the following figures imply that not only increasing the ceiling temperature and consequently the radiant temperature asymmetry to specific values reduces dissatisfaction, but also thermal satisfaction increases in case all body parts are perceived about thermal neutral conditions. However, the PD based on the overall thermal sensation has its minimum at the ceiling temperature of $33^{\circ} \mathrm{C}$ and the PD increases with an increasing ceiling temperature from 33 to $38^{\circ} \mathrm{C}$. Interestingly, the curve obtained based on the TSVs closely follows the guidance curve by Fanger beyond radiant asymmetry temperatures of $8 \mathrm{~K}$. Additionally, the analyses suggest that a further increase of the ceiling temperature may cause local thermal discomfort at some body parts near to the warm ceiling or may cause asymmetric thermal sensation between the head and extremities. The influence of higher ceiling and radiant asymmetry temperatures on the thermal satisfaction will be discussed in the future work. However, for an application in building renovation, with a higher quality of the building envelope, such radiant asymmetry temperatures beyond $8 \mathrm{~K}$ are getting unlikely.

Moreover, according to the former studies done by Fanger [35] for calculation of the percentage of dissatisfaction in the uniform thermal environments, Fanger [5] claimed that the criteria as $5 \%$ dissatisfied participants could presumably be applied for the overhead radiant systems. However, the comparison between Figure 7 and the PPD values obtained based on the satisfaction question shown in Figure 10 clearly indicate that although about $20 \%$ of participants were dissatisfied at the relatively high asymmetry temperatures created by the ceiling temperature of $38^{\circ} \mathrm{C}$, the participants felt "neutral" at the majority of body parts, especially for scenario S12. However, the PD values based on the overall thermal sensation votes have considerably lower values than PD values based on satisfaction question; yet, the values were not below $10 \%$. As seen in Figure 11, interestingly, the PD based on TSVs are about the same as the PPDs by Fanger for an asymmetry between 7.3 and $7.8 \mathrm{~K}$. In the other cases, the PPD underestimated the percentage of dissatisfied. The PPD increased to about "neutral, 0 ", if the ceiling temperature increased.

\section{Conclusions}

In the present study, the potential application of a low-temperature radiant ceiling system in buildings with low- and high-performance façades was evaluated based on the comfort criteria. Subjective experiments (within-subject design) related to twelve scenarios were performed with 30 young subjects (19-30 years old) in an indoor test facility in winter 2017-2018. These scenarios were developed based on a combination of three ceiling surface temperatures $\left(28,33\right.$ and $\left.38^{\circ} \mathrm{C}\right)$, two window temperatures of 15.5 and $19^{\circ} \mathrm{C}$ for imitation of conventional and advanced windows, respectively, and distances of $1 \mathrm{~m}$ and $3 \mathrm{~m}$ to the window. The effect of the radiant heating ceiling system, the cool window, and distance to the cool window on the local thermal sensation and comfort of occupants, thermal sensation asymmetry, and radiant temperature asymmetry was investigated using questionnaires and physical measurements of skin temperature and thermal environmental properties. 
The analyses based on this laboratory research were limited to the scope of this study, where the occupants had winter clothing and wall temperatures were close to room air temperature for a more realistic simulation of conditions in practice. The analyses were limited to the responses of fifteen subjects sitting at one of the two positions in respect to the window, in which the number of participants was vindicated based on former studies $[5,11,15,36]$. From the research that was carried out, the key findings can be summarized as follows:

- Overall, the results imply that the radiant ceiling heating system operating at low temperatures (below or equal to $38^{\circ} \mathrm{C}$ ) can provide about 'neutral' thermal sensations at the majority of body-parts at two positions $(1 \mathrm{~m}$ and $3 \mathrm{~m})$ in respect to both cool and warm windows $\left(15.5\right.$ and $\left.19^{\circ} \mathrm{C}\right)$.

- The warm ceiling operating at 33 and $38^{\circ} \mathrm{C}$ has about the same impact on local thermal sensation and comfort, if the building envelope follows advanced building energy-efficiency regulations.

- Application of highly insulated façade mostly influences local thermal sensation perceived by those occupants, who sit near to the façade, if the radiant ceiling system operates at relatively low temperatures. The temperature of the façade has minimum influence on local thermal sensation at relatively high ceiling surface temperatures.

- Beyond expectation, the head was perceived as the most comfortable body-part, even though the head was the closest body-part to the warm ceiling and it is the most sensitive upper extremity to the warm condition. It is in contradiction with the results presented by Fanger [5], that discomfort due to a warm head happened almost as often as discomfort due to cold feet.

- The results indicated that the PMV index does not assess the perceived thermal feeling of the occupants exposed to asymmetric radiant fields correctly.

- Finally, according to former studies done by Fanger and ASHRAE-55 [5,7], it was claimed that the criteria of $5 \%$ dissatisfied participants could presumably be applied for the overhead radiant systems. The limit of radiant temperature asymmetry corresponding to $5 \%$ dissatisfaction is $4 \mathrm{~K}$. However, our experimental analyses clearly indicate that although more than $10 \%$ of participants were dissatisfied at the relatively high radiant asymmetry temperatures $(7.5 \mathrm{~K})$ created by the ceiling surface temperature of $33^{\circ} \mathrm{C}$, the participants can still feel "neutral" at the majority of body parts. Therefore, the radiant asymmetry temperature of $7.5 \mathrm{~K}$ for the dissatisfaction limit of $10 \%$ is recommended, if occupants have the winter cloth and the operative temperature is in the range that about "neutral" conditions are guaranteed.

Author Contributions: The project funding was acquired by A.W.; M.R.S. and A.W. conceived of and designed the experiments. M.R.S. performed the experiments and the analyses, and wrote the paper; M.S. developed the R-package "comf" for calculations of operative temperature, PMV, and PPD; M.S. and A.W. improved the paper organization and English of the manuscript.

Funding: This work was supported by the Federal Ministry for Economic Affairs and Energy, BMWi, under the project No. 03SBE0001 A (LowEx-Bestand).

Conflicts of Interest: The authors declare no conflict of interest. 


\section{Appendix A}

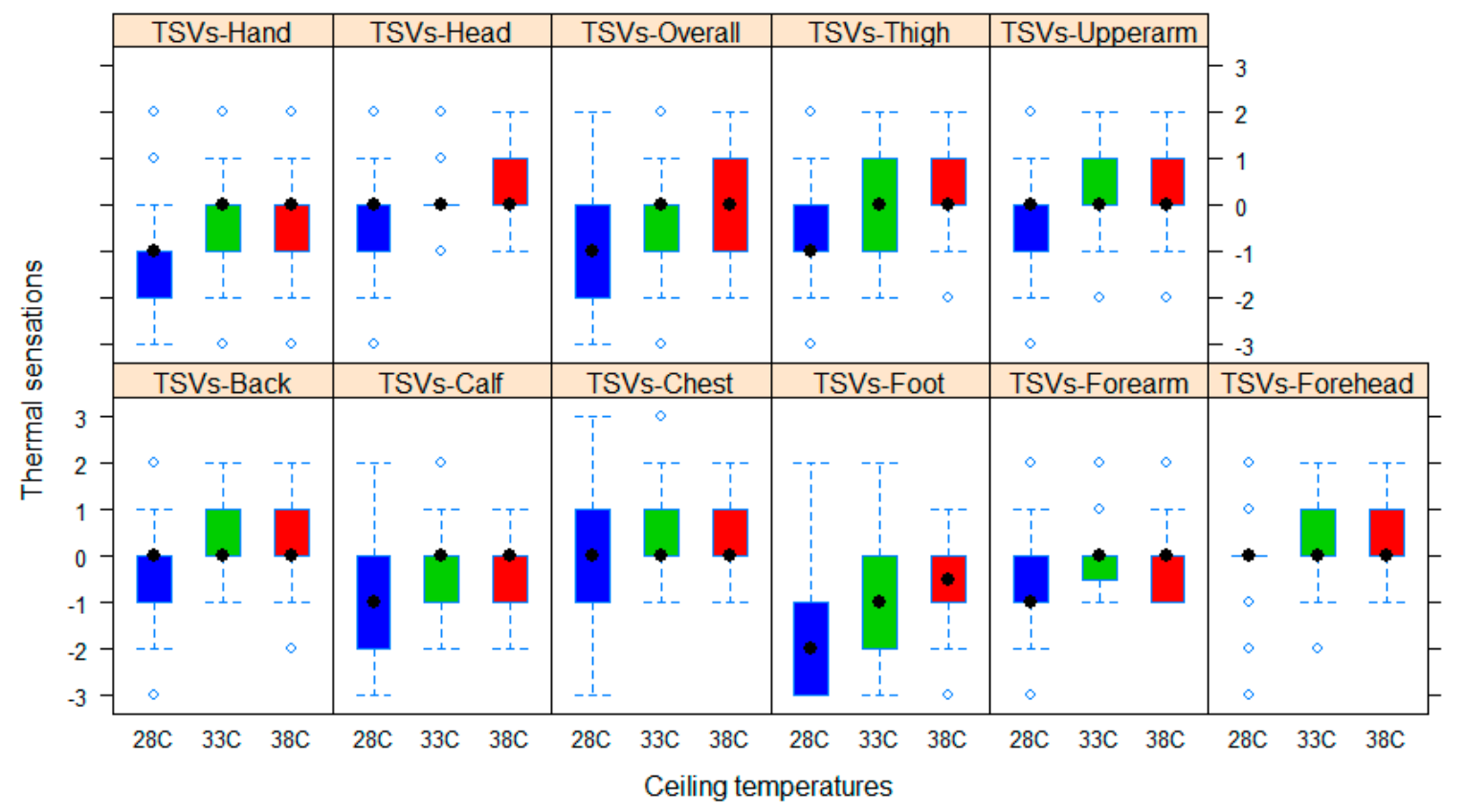

Figure A1. Overall and local thermal sensation votes at 10 body parts corresponding to different ceiling temperatures. TSVs stands for thermal sensation votes.

\section{References}

1. Olesen, B.W.; Parsons, K.C. Introduction to thermal comfort standards and to the proposed new version of EN ISO 7730. Energy Build. 2002, 34, 537-548. [CrossRef]

2. De Dear, R.J.; Akimoto, T.; Arens, E.A.; Brager, G.; Candido, C.; Cheong, K.W.D.; Li, B.; Nishihara, N.; Sekhar, S.C.; Tanabe, S.; et al. Progress in thermal comfort research over the last twenty years. Indoor Air 2013, 23, 442-461. [CrossRef] [PubMed]

3. Chrenko, F.A. Heated Ceilings and Comfort. J. Inst. Heat. Vent. Eng. 1953, 20, 375-396.

4. Griffiths, I.; McIntyre, D. Subjective Response to Overhead Thermal Radiation. Subj. Response Overhead Therm. Radiat. 1974, 16, 415-422. [CrossRef]

5. Fanger, P.O.; Banhidi, L.; Olesen, B.W.; Langkilde, G. Comfort limits for heated ceilings. ASHRAE Trans. 1980, 86, 141-156.

6. Halawa, E.; van Hoof, J.; Soebarto, V. The impacts of the thermal radiation field on thermal comfort, energy consumption and control-A critical overview. Renew. Sustain. Energy Rev. 2014, 37, 907-918. [CrossRef]

7. ASHRAE-55 ANSI/ASHRAE Standard 55-2017: Thermal Environmental Conditions for Human Occupancy; ASHRAE: Atlanta, GA, USA, 2017.

8. Fanger, P.O.; Ipsen, B.M.; Langkilde, G.; Olessen, B.W.; Christensen, N.K.; Tanabe, S. Comfort limits for asymmetric thermal radiation. Energy Build. 1985, 8, 225-236. [CrossRef]

9. Wang, Z.H.; Zhang, H.; Arens, E.; Lehrer, D.; Huizenga, C.; Yu, T.; Hoffman, S. Modeling Thermal Comfort with Radiant Floors and Ceilings. In Proceedings of the 4th International Building Physics Conference, Istanbul, Turkey, 15-18 June 2009; Volume 94, pp. 9-10.

10. McNall, P.; Biddison, R. Thermal and Comfort Sensations of Sedentary Persons Exposed to Asymmetric Radiant Fields; ASHRAE Transactions: San Francisco, CA, USA, 1970; Volume 76.

11. Underwood, P.; Parsons, K.C. Discomfort Caused by Sitting Next to a Cold Window: Simulated Railway Carriage at Night. Available online: https://www.researchgate.net/publication/281572751_ Discomfort_caused_by_sitting_next_to_a_cold_window_Simulated_railway_carriage_at_night (accessed on 25 October 2018).

12. Gan, G. Analysis of mean radiant temperature and thermal comfort. Build. Serv. Eng. Res. Technol. 2001, 22, 95-101. [CrossRef] 
13. Larsson, U.; Moshfegh, B. Experimental investigation of downdraught from well-insulated windows. Build. Environ. 2002, 37, 1073-1082. [CrossRef]

14. Zhang, H. Human Thermal Sensation and Comfort in Transient and Non-UNIFORM Thermal Enviroments; University of California: Berkeley, CA, USA, 2003.

15. Sakoi, T.; Tsuzuki, K.; Kato, S.; Ooka, R.; Song, D.; Zhu, S. Thermal comfort, skin temperature distribution, and sensible heat loss distribution in the sitting posture in various asymmetric radiant fields. Build. Environ. 2007, 42, 3984-3999. [CrossRef]

16. Wyon, D.P.; Larsson, S.; Forsgren, B.; Lundgren, I. Standard procedures for assessing vehicle climate with a thermal manikin. SAE Trans. 1989, 98, 46-56.

17. Nilsson, H.O. Comfort Climate Evaluation with Thermal Manikin Methods and Computer Simulation Models. Indoor Air 2003, 13, 28-378. [CrossRef] [PubMed]

18. Huizenga, C.; Zhang, H.; Mattelaer, P.; Yu, T.; Arens, E.; Lyons, P. Window Performance for Human Thermal Comfort. Center for the Built Environment; University of California: Berkeley, CA, USA, 2006.

19. Zhang, H.; Arens, E.; Huizenga, C.; Han, T. Thermal sensation and comfort models for non-uniform and transient environments, part III: Whole-body sensation and comfort. Build. Environ. 2010, 45, 399-410. [CrossRef]

20. Fiala, D. Dynamic Simulation of Human Heat Transfer and Thermal Comfort; De Montfort University: Leicester, UK, 1998.

21. Wagner, A.; O'Brien, W.; Dong, B. Exploring Occupant Behavior in Buildings; Wagner, A., O'Brien, W., Dong, B., Eds.; Springer International Publishing AG: Cham, Switzerland, 2017.

22. Safizadeh, M.R.; Wagner, A. Evaluation of Radiant Ceiling Heating Systems for Renovated Buildings Based on Thermal Comfort Criteria. In Proceedings of the 10th Windsor Conference: Rethinking Comfort, Windsor, UK, 12-15 April 2018; pp. 128-142.

23. Zhang, H.; Arens, E.; Huizenga, C.; Han, T. Thermal sensation and comfort models for non-uniform and transient environments: Part I: Local sensation of individual body parts. Build. Environ. 2010, 45, 380-388. [CrossRef]

24. Arens, E.; Zhang, H.; Huizenga, C. Partial- and whole-body thermal sensation and comfort, Part II: Non-uniform environmental conditions. J. Therm. Biol. 2006, 31, 60-66. [CrossRef]

25. Schweiker, M.; Mueller, S.; Kleber, M.; Kingma, B.R.; Shukuya, M. R Package: 'Comf'. R Core Team and Contributors Worldwide. Available online: https://cran.r-project.org/web/packages/comf/comf.pdf (accessed on 24 October 2018).

26. Romana, F.; Alfano, A.; Dell'Isola, M.; Palella, B.I.; Riccio, G.; Russi, A.; d'Ambrosio Alfano, F.R.; Dell'Isola, M.; Palella, B.I.; Riccio, G.; et al. On the measurement of the mean radiant temperature and its influence on the indoor thermal environment assessment. Build. Environ. 2013, 63, 79-88. [CrossRef]

27. R Package: Stats. Version 3.6.0. R Core Team and Contributors Worldwide. Available online: https://stat.ethz.ch/ R-manual/R-devel/library/stats/html/00Index.html (accessed on 24 October 2018).

28. Schellen, L.; Loomans, M.G.L.C.; De Wit, M.H.; Olesen, B.W.; Lichtenbelt, W.D.V.M. Effects of different cooling principles on thermal sensation and physiological responses. Energy Build. 2013, 62, 116-125. [CrossRef]

29. Wong, N.H.; Khoo, S.S. Thermal comfort in classrooms in the tropics. Energy Build. 2003, 35, 337-351. [CrossRef]

30. Wong, N.H.; Feriadi, H.; Lim, P.Y.; Tham, K.W.; Sekhar, C.; Cheong, K.W. Thermal comfort evaluation of naturally ventilated public housing in Singapore. Build. Environ. 2002, 37, 1267-1277. [CrossRef]

31. Schweiker, M.; Fuchs, X.; Becker, S.; Shukuya, M.; Dovjak, M.; Hawighorst, M.; Kolarik, J. Challenging the assumptions for thermal sensation scales. Build. Res. Inf. 2016, 45. [CrossRef]

32. Lyons, P.; Arasteh, D.; Huizenga, C.; Senyupta, J.; Chapman, K.S.; Keshavarz, A. Window performance for human thermal comfort. ASHRAE Trans. 2005, 35, 254-275.

33. Fanger, P.O. Thermal Comfort Analysis and Applications in Environmental Engineering; Danish Technical Press: New York, NY, USA, 1970. 
34. Hoyt, T.; Schiavon, S.; Piccioli, A.; Moon, D.; Steinfeld, K. CBE Thermal Comfort Tool. Available online: http:/ / comfort.cbe.berkeley.edu/ (accessed on 28 July 2018).

35. FANGER. Moderate Thermal Environments Determination of the PMV and PPD Indices and Specification of the Conditions for Thermal Comfort; ISO 7730; ISO: Geneva, Switzerland, 1984.

36. Olesen, S.; Fanger, P.O.; Jensen, P.B.; Nielsen, O.J. Comfort Limits for Man Exposed to Asymmetric Thermal Radiation. In Proceedings of the Thermal Comfort Moderate Heat Stress, London, UK, September 1972; pp. 133-148. Available online: http:/ / www.cbe.berkeley.edu/research/other-papers/Olesen\%20et\%20al\% 201972\%20Comfort\%20limits\%20for\%20man\%20exposed\%20to\%20asymmetric\%20thermal\%20radiation. pdf (accessed on 24 October 2018).

2018 by the authors. Licensee MDPI, Basel, Switzerland. This article is an open access article distributed under the terms and conditions of the Creative Commons Attribution (CC BY) license (http://creativecommons.org/licenses/by/4.0/). 